\title{
The Client Voices Pilot: Managing knowledge in the NGO sector in Aotearoa-New Zealand
}

By

\section{Jarrod Rendle}

\begin{abstract}
A thesis
Submitted to the Victoria University of Wellington in partial fulfilment of the requirements for the degree of Master in Development Studies
\end{abstract}

Victoria University of Wellington 


\section{Acknowledgements}

The Author wishes to thank the following organisations and their associated staff for their contribution to this thesis and their hard work and professionalism shown throughout the Client Voices project:

New Zealand Federation of Family Budgeting Services

Whangarei Budget Service

Manawatu Home Budget Service

The Porirua Budget Service

Lower Hut CAB Budget Service

Timaru Budget Advisory Trust

Dunedin Budget Service

The Author would also like to thank the NZFFBS National Board for the guidance and wisdom that they have always offered so graciously. 


\section{Dedication}

The Author would like to dedicate this book to the two most important people in his life. The first dedication is to Ingrid for teaching me how to dream and the second is to Alayna for teaching me how to believe in them. These women were put on this earth to teach and I am humbled by the good fortune of being student to both. My lifelong lessons are far from over but I have at least developed one formula to surmise what I have learnt thus far:

Dreams $=$ Imagination + Reality

I will never stop dreaming... 


\begin{abstract}
The purpose of this thesis is to present the Client Voices pilot project as an example of the type of knowledge management system that non-government organisations in the community and development sectors can use to leverage competitive advantage for their long term success. The four major knowledge management issue themes: connectivity, collaboration, content and capacity are discussed in detail throughout the thesis. The organisations, legislation, project background work and funding issues that created the environment for the Client Voices project are outlined. Following this an examination of the theory behind both knowledge management and competitive advantage is offered with a number of real-life, practical examples used for descriptive purposes. The Client Voices pilot project is then discussed in some detail in terms of the methodology employed as well as the fieldwork that undertaken. A critical analysis of the project is then presented using the four major issues themes and a number of recommendations are made for development practitioners and academics alike. Finally, the findings of the thesis are reiterated, the implications of both the Client Voices project and knowledge management in the NGO sector are posed and the effects of globalisation on grass roots NGOs as well as an alternative growth model are considered.
\end{abstract}


Title Page

Acknowledgements

Dedication iii

Abstract iv

Contents $\quad$ v

Acronyms

Chapter 1 Introduction $\quad 1$

2.1 Methods 2

2.1 Outline 3

Chapter 2 A Policy Path Toward the Client Voices Pilot 5

2.1 The New Zealand Federation of Family Budgeting Services Inc 6

2.2 Measuring the Social Effect of Government Policy 7

2.3 Credit Contracts and Consumer Finance Act 9

2.4 Developing a Knowledge Management Framework 10

2.5 Funding Shortfalls: The twenty-seven become seven 12

Chapter 3 Managing Knowledge $\quad 14$

3.1 Knowledge Management in the Development Sector 14

3.1.1 Connectivity 16

$\begin{array}{lll}3.1 .2 & \text { Collaboration } & 17\end{array}$

$\begin{array}{lll}3.1 .3 \text { Content } & 19\end{array}$

3.1.4 Capacity 20

3.2 Practical Applications: Connectivity, collaboration, content and capacity 22

3.2.1 Connectivity: People First Network - Solomon Islands 22

3.2.2 Collaboration: Ayuda Urbana - Central AmericaCaribbean $\quad 24$

3.2.3 Content: Collecting and Exchange of Local Agricultural Content Project - Uganda 26

3.2.4 Capacity: Improving Farm Production and Smallholder
Farmer Market Awareness - Sri Lanka

Chapter 4 Managing Knowledge for Competitive Advantage 30

4.1 Competitive Advantage and ICT 30

4.2 Leveraging Competitive Advantage in the NGO Sector 33

4.2.1 Funding - Chasing the money-go-round 33

4.2.2 Resources - He tangata, he tangata, he tangata 34

$\begin{array}{ll}\text { 4.2.3 } & \begin{array}{l}\text { Specialisation or Utilisation - Creating sustainable } \\ \text { competitive advantage }\end{array}\end{array}$

4.2.4 Grow or Die - Employing transformation theory in the
NGO sector

Chapter 5 The Client Voices Pilot 40

5.1 Methodology 40

$\begin{array}{lll}\text { 5.1.1 Objectives and Goals } & 40\end{array}$

5.1.2 Project Participants 40

5.1.3 Technical Skill Requirements 40

5.1.4 Governance and Process Development 42

5.1.5 The Client Voices Database 42 
5.1.6 Training, Testing and Rollout 43

5.1.7 Monitoring and Review 43

$\begin{array}{lll}5.1 .8 & \text { Timeline } & 44\end{array}$

5.1.9 Funding and Budget 44

$\begin{array}{lll}5.2 \text { Fieldwork } & 44\end{array}$

5.2.1 Member Consultation 44

5.2.2 Workframe Development 45

5.2.3 Participatory Workshop 45

5.2.4 Form Development 46

5.2.5 Governance Process 47

5.2.6 Fundraising 47

5.2.7 Database Development 48

5.2.8 Service Contracts $\quad 51$

$\begin{array}{ll}5.2 .9 \text { Training } & 51\end{array}$

5.2.10 Database Testing $\quad 52$

5.2.11 Project Monitoring $\quad 53$

5.2.12 Rollout $\quad 54$

5.2.13 Review $\quad 55$

Chapter 6 Critical Analysis and Recommendations 56

$\begin{array}{lll}6.1 \text { Connectivity } & 56\end{array}$

$\begin{array}{lll}6.1 .1 & \text { Recommendations } & 58\end{array}$

$\begin{array}{ll}6.2 \text { Collaboration } & 58\end{array}$

$\begin{array}{lll}\text { 6.2.1 Recommendations } & 59\end{array}$

$\begin{array}{ll}6.3 \text { Content } & 60\end{array}$

6.3.1 Recommendations 62

6.4 Capacity $\quad 62$

6.4.1 Recommendations $\quad 64$

$\begin{array}{ll}\text { Chapter } 7 \text { Conclusion } & 65\end{array}$

7.1 Looking Forward $\quad 66$

$\begin{array}{lll}7.2 & \text { Global Implications } & 68\end{array}$

\section{Bibliography}

Appendix i

Appendix ii

Appendix iii

Appendix iv

Appendix $v$

Appendix vi 


\section{Acronyms}

ICTs - Information and Communication Technologies

IT - Information Technology

KM - Knowledge Management

GNI - Gross National Income

CABI - CAB International

UCCI - Union of Capital Cities of Ibero-America

NGO - Non-Government Organisation

MCA - Ministry of Consumer Affairs

NZFFBS - New Zealand Federation of Family Budgeting Services

CCCFA - Credit Contracts and Consumer Finance Act

UN - United Nations

UNDP - United Nations Development Programme

PFnet - People First Network

UCCI - Union of Capital Cities of Ibero-America

CABI - CAB International

CELAC - Collecting and Exchange of Local Agricultural Content

BROSDI Busoga Rural Open Source and Development Initiative

CPF Community Partnership Fund

ICT4D - Information and communication technologies for development

KM4D - Knowledge management for development

FTP - File Transfer Protocol 


\section{Chapter One - Introduction}

\footnotetext{
The ability to store, share, and analyse knowledge through networks and communities using the new ICT technologies allows firms to exploit the unique properties of knowledge to gain competitive advantage. Perhaps the most important property is that knowledge is the ultimate economic renewable - the stock of knowledge is not depleted by use... (Brinkley, 2006, p. 5)
}

'Knowledge is power' Sir Frances Bacon once said. This is a fairly lofty status and one that is possibly unwarranted. Perhaps what is somewhat closer to the truth is that 'knowledge is a resource'. Like resources it can be harvested, contained and redistributed. Like scarce resources it also has considerable economic potential. Knowledge is the 'ultimate economic renewable' according to Brinkley (2006). In the above quote, however, the resource is being utilised by private firms whereas the economic value of knowledge has just as much relevance in not-for-profit organisations as it does in for-profit ones. Indeed it would be to the benefit of a nation's economy to bear this point in mind.

The purpose of this thesis is to present the Client Voices pilot project as an example of the type of knowledge management system that non-government organisations (NGO) in the community and development sectors can use to leverage competitive advantage for their long term success. The four major knowledge management issue themes: connectivity, collaboration, content and capacity, as acknowledged in the Cambridge University Press 4CInitiative (2008), are discussed in detail throughout the thesis both in relation to the current body of literature on knowledge management as well as in the critical analysis of the Client Voices knowledge management project itself.

Theoretical analysis of the management of knowledge in the development sector is a relatively new strand of academic research that comes from the much larger research area of information and communication technologies. This area of research is so contemporary that the first issue of the Knowledge Management for Development Journal was only released in 2005.

Although knowledge management in the private sector has been discussed academically for a number of years, for instance by Nonaka \& Takeuchi (1995), Davenport \& Prusak 
(1998), Denning (1998), Wilmott (1998) and Kinney (1998) among many others, it is only relatively recently that it has been discussed in relation to the NGO sector.

Moreover, knowledge management and its relationship to competitive advantage has been well covered for the private sector, for instance by Fulmer et al. (1998), Hildebrand (1999), Argot \& Ingram (2000), Carneiro (2000), and Ndlela \& Toit (2001) among others, but there is very little research in this area with regard to the NGO sector.

The relatively few authors currently covering this significant aspect of knowledge management include Hurley \& Green (2005), Safa et al. (2006), and Kong (2007). Achieving competitive advantage through knowledge management in the NGO sector is clearly an area demanding more research and this thesis will help to contribute to this small but growing pool of knowledge.

\section{Method}

This thesis is based on the findings from a pilot project managed by the New Zealand Federation of Family Budgeting Services Inc (NZFFBS). The project, known as the Client Voices project, was conducted over the period July 2006 to June 2007 with a substantial amount of preliminary work undertaken prior to July. The pilot project team consisted of members from five Aotearoa-New Zealand budget services as well as the Chief Executive Officer (oversight) and Information \& Policy Officer (project manager) from the NZFFBS. The project manager is also the author of this thesis.

Various references are made to the project team throughout the thesis. This is particularly the case in Chapter Five, which discusses the project methodology and fieldwork in some detail. Whenever a reference is made to the project team in relation to the Client Voices project it is a team that was managed by the author. A number of references are also made to material that was written by the author for the purposes of the Client Voices project; this material has been included in the Appendix section of the thesis. As project manager of the Client Voices project the author was afforded considerable insight into knowledge management projects, which has been included throughout the thesis; in particular, in the critical analysis and recommendations in Chapter Six. The author has endeavoured to remain objective with the facts provided. 


\section{Outline}

The second chapter of this thesis is entitled A Policy Path Toward the Client Voices

Pilot. This chapter briefly outlines the organisations, legislation, project background work and funding issues that together created the environment for the Client Voices pilot project to develop. The New Zealand Federation of Family Budgeting Services Inc, the first section in this chapter, provides a brief background to the organisation managing the Client Voices project. In Measuring the Social Effect of Government Policy the Ministry of Consumer Affairs is introduced and an explanation as to why this government department got involved in the project is provided. The legislation that provided the need for knowledge is outlined in Credit Contracts and Consumer Finance Act. Finally, a behind-the-scenes look at the steps taken leading up to the project start date is presented in both Developing a Knowledge Management Framework and the last section Funding Shortfalls: The twenty-seven become seven.

The third chapter, Managing Knowledge, takes a look at the growing volume of literature in the relatively new field of knowledge management in the development sector (for the purposes of this thesis the community and development sectors are considered as broadly the same fields and the terms are used interchangeably throughout). The first section, Knowledge Management in the Development Sector, briefly discusses what knowledge management is and then considers it in the context of development studies. The second section, Practical Applications: Connectivity, collaboration, content and capacity, takes four contemporary knowledge management projects from the development sector and shows how they fit into one of the four key issues themes outlined above.

The next chapter, Managing Knowledge for Competitive Advantage, begins with the section Competitive Advantage in Relation to Knowledge Management, which outlines what competitive advantage is and considers it in relation to technology and knowledge management. In Leveraging Competitive Advantage in the NGO Sector a number of facts regarding the community sector are described. Competitive advantage, again in relation to knowledge management, is then considered in terms of current NGO practice in relation to these facts.

The fifth chapter, The Client Voices Pilot, discusses the fieldwork component of the Client Voices pilot project. First, in Methodology, the pilot project methodology is 
discussed in some detail. Nine sections are used to breakdown the methodology into specific project work areas. The second section, Fieldwork, explores each of these areas in further detail under 13 section headers and describes the work undertaken at each point during the project.

The sixth chapter in this thesis, Critical Analysis and Recommendations, revisits the four major issues themes Connectivity, Collaboration, Content and Capacity to critically analyse the Client Voices project. At the end of each of these sections is a recommendations section that uses the experience gained on the Client Voices project to offer a number of practical ideas for knowledge management projects in the NGO sector.

Conclusion, the seventh and final chapter, begins by looking back over the findings of the thesis and reiterates the major points that were made throughout. After looking backward, the section Looking Forward considers the implications of both the Client Voices project and knowledge management in the NGO sector more generally for the future. Finally, in Global Implications, this last chapter takes the findings and implications from the thesis and poses what they mean at the global level. This discussion includes the effects of globalisation on grass roots NGOs as well as offering an alternative growth model that NGOs could construct at the global level in the future. 


\title{
Chapter Two - A Policy Path Toward the Client Voices Pilot
}

\begin{abstract}
In the dominant development strategy of growth grounded in modernization, the state's role was to intervene, assist and often direct the form... development took. A series of socio-political and economic changes has, however, called [this] into question... The state is receding and looking for new partners to help implement and fund social and development programmes... Many are slowly coming to accept elements of the neo-liberal argument that the public and centralized institutions have inherent inefficiencies. (Bebbington
\end{abstract} \& Thiele, 1993, p. 200)

As Bebbington and Thiele suggest, many people from different sectors have now come to recognise the inherent inefficiency of one, centralised department creating, interpreting, enforcing, measuring and then redeveloping public policy. That is not to say, however, that the market should necessarily pick up any of these roles. Neo-liberal dogma might purport that free markets offer perfect flows of information and should, therefore, be a 'perfect' system for measuring the social effects of public policy. In Aotearoa-New Zealand, where neo-liberal reform has left much to be desired, this is unlikely to be an option that would be considered.

On any number of metrics, the great Aotearoa-New Zealand experiment in neo-liberal reform has been shown to be an abject failure. Conway (2002), for instance, states that at the end of the reforms:

... the New Zealand of 1999 exhibited all the signs of a divided society - between rich and poor, employers and workers, even city and country. The experiment had failed, not only in a fundamental economic sense, but also in terms of social inclusion and welfare. (p. 2)

This is certainly not the sort of system that should be used to make assessments of the social impact of legislation. It stands to reason, then, that if inefficient government departments are too remote and under-resourced and the laissez-faire market is, by its very nature, unable to intervene in its own process of creating 'losers' then civil society ought to be well positioned to assess the effects of public policy on the public; a process that civil society, by its very nature, has a vested interest in seeing done fairly and equitably. 
Civil society organisations have direct access to the markets they represent, they are generally perceived in a more trustworthy light than public and private institutions (Narayan \& Petesch, 2002), and are often already actively influencing government policy through their advocacy roles. Further, civil society organisations are working much more closely with the private sector now through both their more traditional advocacy roles as well as more recently through direct investment from the private sector by way of outcome-focussed, corporate sponsorship. For these reasons, civil society is well placed to work with both the public and private sectors to measure the social effect of various policies on the public as well as helping to promote and inform debate based on good-quality information. A civil society organisation in Aotearoa-New Zealand is pursuing just such a strategy.

\section{The New Zealand Federation of Family Budgeting Services Inc}

The New Zealand Federation of Family Budgeting Services (NZFFBS) is an NGO in Aotearoa-New Zealand. It is the umbrella body for a collective of community organisations that provide budget advice under a shared philosophy. The NZFFBS states its mission as being "...dedicated to the development and education of budgeting skills through free advice and community programmes from supportive, confidential and culturally aware services" (NZFFBS, 2007, [online]).

The NZFFBS currently comprises a membership of 149 organisations under four different membership types and is supported by its national office based in Wellington, Aotearoa-New Zealand. The national office is staffed by six, full-time paid employees and 41 volunteers representing different regions and districts throughout the country. Its members collectively worked with more than 29,000 clients over the 12 month period to 30 June 2007 . This service was delivered by over 800 predominantly volunteer budget advisers and more than 400 support staff (NZFFBS, 2007).

The organisation was born out of a service originally supported by the then Ministry of Social Welfare in the 1960s. The original service was community-based, run by volunteers and had a very definite focus on both Maori and woman clients. It evolved somewhat haphazardly before a national organisation was set up in the 1970s and national training standards and service delivery began to be developed. 
Thirty years later the organisation is stronger than ever and still run predominantly by volunteers (although there are many more paid staff now due, in part, to the professionalisation era of the service during the 1990s). The organisation still targets programmes specifically to Maori clients, which make up around 42 percent of its client base (NZFFBS, 2007) and, more recently, has begun to target programmes for Pacific Islanders and other migrants. The budget services are still supported by the Ministry of Social Development, although their total government grant has dropped away to between 40 and 60 percent of their total funding (this information is from a confidential policy paper).

Interestingly, budget services do not fundraise directly from the community. This is part of the philosophy that they subscribe to in belonging to the network. This is an anomaly that came about due to the services' originally being very well funded and resourced by the government and a moral stance where it was deemed unethical to ask for money from the same community in which they were teaching money management skills. Although this was a morally rewarding position to take by the budget services, it meant that other funding sources needed to be found. This became much more evident once the government began systematically reducing its levels and availability of funding to the community sector; a system poorly disguised by neo-liberal marketing, such as 'user-pays', 'student loans', 'deregulation' and 'public-good' measures, unleashed during the 1980s and 1990s.

The NZFFBS has been very active, although not necessarily always successful, in seeking out new areas of funding to access. Various service delivery contracts have been chased over the last few decades including targeted support for beneficiaries, education programmes for prison inmates, education programmes for the wider community, organisational capacity building, and more recently running a free-phone service as part of the Government's KiwiSaver initiative and collecting information on consumer legislation.

\section{Measuring the Social Effect of Government Policy}

In Aotearoa-New Zealand a number of government departments are now actively seeking from the community sector quality information on the effect their legislation has on the public (for instance the Ministry of Health's Strategic relationship framework, the Ministry of Social Development's Pathway to Partnership programme 
and the Ministry for the Environment's Talk Environment Roadshow). It is critical for these departments to make decisions based on high-quality and readily available data.

One such department has openly recognised its own inefficiencies in the data-gathering process and begun to develop partnerships with both the private sector and civil society in order to gain access to their knowledge. The Ministry of Consumer Affairs (MCA) is a smaller department within the Ministry of Economic Development and its role is to create an environment in Aotearoa-New Zealand in which consumers can transact with confidence. MCA has identified a number of key challenges for consumer policy:

- The changing age and ethnic profile of consumers

- Potential shifts in attitudes amongst consumers themselves

- Changing market practices resulting from new technology, but also simply from the ways suppliers adapt products, services and behaviour to attract and retain customers and in response to the way markets are designed

- How best to approach information "overload" issues; [and]

- Globalisation (MCA, 2003, p. 8)

The MCA review that identified these challenges concluded that the Ministry's primary role was, “... to create an environment that is conducive to good and accurate information flows between suppliers and consumers so that consumers can transact with confidence" (2003, p. 8). In order to create this environment MCA needs to gather information about the effect of various transactions on consumers and, in particular, on those transactions where consumers are detrimentally affected.

The review also identified a number of areas that MCA should address in order to fulfil its primary role, including:

- Fully exploiting the ability of the operational arms of the Ministry to gather "intelligence" about consumer issues

- Strengthening the links between policy and operations, particularly those between the Policy Team and the Consumer Information Service

- Better utilising and extending its networks and contacts with consumers and businesses

- Improving access to and addressing gaps in consumer data

- Further developing its capability to research or contract research on consumer issues; [and] 
- Enhancing its ability to monitor and evaluate the impacts of consumer policy.

(MCA, 2003, p. 9)

In all of these areas the Ministry is considering its data-gathering ability and, at the same time, identifying its limitations. Each of these areas gives good reason for MCA to enhance its networks in the community sector. The close working relationship MCA has developed with the NZFFBS over a number of years is an outcome of MCA working to address the needs above. Until recently this relationship model was based on reciprocity and information-sharing. More recently, however, this relationship has become more formalised. New consumer legislation has required MCA to address point five above more closely to measure the effect of that legislation in practice.

A Memorandum of Understanding was signed between the two organisations with the explicit outcome of "...furthering their common goal of assisting consumers" (2005, pg. 1). This document outlined a number of expectations from both parties and included the following three promises made by the NZFFBS:

- To provide comment to the Ministry on key issues for reform and development of consumer law, as negotiated between the Ministry and the Federation

- To provide case studies to the Ministry on consumer issues of agreed mutual concern, having regard to the need of services to maintain client confidentiality; [and]

- To provide relevant information to its members on consumer issues and encourage them to participate in Consumer Representative forums (2005, pg. 3)

The information-sharing provisions in the memorandum cover the entire consumer environment in which the NZFFBS and MCA work in. It is in the credit sector, however, that the NZFFBS derives most of its knowledge and it was this sector that MCA particularly required information for. This need for information became even more pressing after April 2005 when a new law was introduced that focussed specifically on the lending and borrowing practices in Aotearoa-New Zealand.

\section{Credit Contracts and Consumer Finance Act}

On 1 April 2005 new rules in the Credit Contracts and Consumer Finance Act 2003 (CCCFA) came into force. The new Act covers a range of lending practices including home loans, personal loans, hire purchase agreements, credit cards, long-term leases and 
housing buy-back schemes. The purpose of the CCCFA is to "... provide transparency in dealings between creditors and debtors. The Act allows creditors considerable flexibility in the manner in which they comply with their obligations under the Act, while remaining strong against oppressive conduct by creditors" (MCA, 2007, [online]).

More specifically, the CCCFA introduced three new concepts into the lending environment, which were hardship provisions, fees and disclosure that the Commerce Commission would seek to enforce:

- New hardship provisions will provide a framework for contracts to be varied where the consumer unexpectedly find themselves in financial difficulty due to a significant change in personal circumstances (such as redundancy)

- Lenders will no longer be able to charge consumers "unreasonable" fees and penalties, and will be prevented from using unfair methods of calculating interest or early repayment charges; [and]

- New disclosure requirements aim at ensuring that the information lenders provide is understandable and accurate. It's hoped this will assist consumers to make informed decisions about the affordability of a credit agreement, before they sign up to it, and that it will make it easier for consumers to compare the true costs of different credit offerings. (Consumer's Institute, 2007, [online])

The new law also gives the New Zealand Commerce Commission a range of enforcement powers to take action against lenders that act oppressively or otherwise disadvantage debtors in some way. This is a change from the previous environment where consumers had to take their own cases against lenders. This was an expensive, time-consuming and inequitable process that meant the law often went un-enforced (Consumer's Institute, 2007).

\section{Developing a Knowledge Management Framework}

The NZFFBS has been established for more than 30 years and very many of its personnel have well over 10 years experience working in the field. An ongoing work programme was coordinated toward the end of the 1990s focussing on the organisation's overall information collection systems to try to tap into some of this knowledge. Still, the Client Voices project team (as it would come to be known) decided very early on that the current NZFFBS's systems and practices were neither 
robust enough nor were they consistent enough to be able to provide MCA with the 'intelligence' it required to measure the social effect of the CCCFA.

A number of in-depth brainstorming sessions were held early on between representatives of the NZFFBS and MCA. These sessions were very thorough and ensured the NZFFBS representatives thought very critically about their own organisation. In the beginning, the sessions were very much about building up trust in order to break down the defences of the NZFFBS staff so that they could look at their own organisation with 'new eyes'. The final analysis that came out of those sessions was certainly critical, yet also very positive. Essentially, it showed that the NZFFBS was doing the right things but needed to do them much better and, although it did the little things well, it needed to learn not to become bogged down by those things and to always keep one eye fixed on the 'bigger picture'.

Right from the outset it was clear that developing a knowledge framework for the NZFFBS to work within would allow it to continue to improve its own services whilst collecting the knowledge it needed to become a big picture thinker. A system for managing this knowledge was worked through and a conceptual working model was developed. The NZFFBS project team called this the Framework and the name for the framework Client Voices began to be used as a working title. Originally this name was associated just with a database for collecting client data. The idea for this was that the NZFFBS could build the stories of both its advisers and clients into the overall information system. The working title eventually caught on as a project name and began to be used to describe the whole, Federation-wide, knowledge management system.

In the middle of the Client Voices Framework (Appendix i) is the information collection system (the basis of the Client Voices pilot project). Feeding into this system is the collective knowledge of the NZFFBS member budget services. Coming out of the information system is expert knowledge and there is an immediate feedback loop here going directly back to the services. The feedback loop is immediate because only a small amount of information collation and analysis needs to be conducted on the raw collective knowledge extracted from the information system before it can be reused by the budget services. 
From this point there are two further paths that the information can take. Both of these paths require substantial analysis and repackaging of the collected knowledge before they can be taken. Essentially, this is where the NZFFBS can take its own collective knowledge and add value to it turning it into something new. On the left hand side of the Framework are two additional services that expert knowledge would allow the NZFFBS to pursue, financial education and expert commentary. On the right hand side are three areas where new potential funding streams could be accessed, information sales, research and expert advice.

With this document in hand the NZFFBS project team had a working model of their concept that they presented, first to their National Board, and then at the organisation's Annual General Meeting. In both instances the Framework helped to demystify a lot of the necessary jargon that the project used and created a visual path to a goal that benefited all of the meeting delegates. The idea behind the project was accepted by the membership and the project team were given a green light to begin working on the fundamentals and to seek out possible sources of start-up funding.

\section{Funding Shortfalls: The twenty-seven become seven}

Funding the Client Voices project was always going to be difficult and was given the highest risk priority in the Project Risk Management Plan (Appendix ii) accordingly. The original mitigation strategy was to push out the project for three months and then for another three months until funding could be established. The project is predominantly a technology-based one and large outlays for hardware and administration costs were forecast in the original project budget.

A number of medium funding amounts had already been secured in the lead up to the project that had a combined total of $\$ 110,000$. Unfortunately, having this funding pool to draw from made the project team think in big terms. The original project budget came to a grand total of $\$ 396,540$ in the first year alone. The rationale behind this being that the project team expected to secure a government grant from a new fund that was released in 2006 called the Community Partnership Fund (CPF). With a total funding pool of more than $\$ 17$ million the CPF was focused on funding community-based technology projects and had specific application criteria for projects with budgets of over $\$ 100,000$ (Digital Strategy, 2008). The project team applied for $\$ 198,270$ from the first round and were ultimately unsuccessful. 
In the second round of the CPF the project and its costs were scaled back significantly. The original project plan involved 26 budget services and the NZFFBS, with 26 database administrators and three project managers. The revised project scaled this number back to just six services, the NZFFBS and two project managers. The revised Project Budget (Appendix iii) came to a total of $\$ 157,868.75$ in the first year. From this amount the project team applied to the CPF for $\$ 68,655$ in the second round and, again, unfortunately were declined. The intended third round of the CPF did not occur as all of the funding was released during the first two rounds.

At this point the new project plan was taken back to the NZFFBS National Board for a decision to be made as it is NZFFBS policy to never begin a project until all of the funding has been secured. When the Board revisited the project budget it was found that a number of costs that were included in the budget were covered. For instance, $\$ 16,959$ was included for broadband services that would be donated and a total of $\$ 60,160$ was included for costs incurred by NZFFBS staff. Removing these amounts from the budget showed that the underlying costs came to around $\$ 80,000$ and that this total had already been raised from other sources. The Board gave a green light to the project and renamed it a 'pilot' to highlight that it would be the first of multiple stages. The Client Voices Pilot project was born. 


\title{
Chapter Three - Managing Knowledge
}

\author{
This new technology greatly facilitates the acquisition and absorption \\ of knowledge, offering developing countries unprecedented \\ opportunities to enhance educational systems, improve policy \\ formation and execution, and widen the range of opportunities for \\ business and the poor. (World Bank, 1998, p. 9)
}

This 'new technology' the World Bank considers has also helped to create an entirely new branch of development studies theory known as information and communication technologies for development (or ICT4D). This branch of study has increased exponentially over the last 10 years and now includes a number of sub-branches accumulating stocks of literature themselves. One of these branches is known as knowledge management for development (also known as KM4D).

This chapter takes a look at the growing volume of literature in the new field of knowledge management for development. The chapter is split into two sections. The first section Knowledge Management in the Development Sector briefly discusses what knowledge management is and then considers what it means in the context of development studies. Four broad issues themes are used to separate the literature into areas that cause the greatest issues in knowledge management projects: connectivity, collaboration, content and capacity.

These four themes are again revisited in the second section Practical Applications: Connectivity, collaboration, content and capacity. This section takes four contemporary knowledge management projects from the development sector and shows how they fit into one of the four issues themes. Although each of the projects will have issues that fall into all of the themes they have been specifically chosen to highlight the novel way they have overcome one of these issues.

\section{Knowledge Management in the Development Sector}

Theoretical analysis of knowledge management in the development sector is a fairly recent academic strand of the much larger study of utilising information and communication technologies (ICTs) for development. Knowledge management (KM) in the context of this thesis is that as defined by Kannappanavar, et al. (2007), "the process of systematically and actively managing and leveraging the stores of knowledge in an 
organisation is called knowledge management. It is the process of transforming information and intellectual assets into enduring value."

Implicit in the KM concept is the need for some form of ICT that can be used for any or all of the following tasks: extracting, collecting, compiling, storing, monitoring, analysing, reviewing, adding value to and distributing knowledge. The need for the use of ICT comes from the need to digitise the knowledge being collected in order to make it more manageable. As van der Velden (2002) states, “... knowledge management views information as something that is self-contained and that can be stored in a digital format on computers. Hence there is a focus on information technology" (p.3).

There is plenty of debate in the literature about just what constitutes the knowledge aspect of KM ( for example Nonaka \& Takeuchi (1995), Davenport et al. (1998), Davenport \& Prusak (1998), Denning (1998), Wilmott (1998), Mitchell (2000), Dueck (2001), Kakabadse (2001), Oluic-Vukovic (2001)). Most commentators, however, tend to agree that knowledge in the KM context is more than just information and includes the tacit knowledge of individuals within an organisation. Tacit knowledge in the KM context is generally accepted as that defined in Polanyi's (1967) The Tacit Dimension and is emphasised by his aphorism 'we can know more than we can tell'.

So knowledge in this sense is what people 'know'. Unfortunately, people can often find it difficult to tell others exactly what it is that they 'know'. This transferring of knowledge process is made more difficult due to people not even necessarily being conscious of what it is that they know (Denning, 1998). The fact that knowledge is such a difficult concept to define means the tools and processes chosen during the design phase in a KM project to transfer it need to be very carefully considered. Denning (1998) asserts that, “... the development of tools that support knowledge sharing in an appropriate and user-friendly way, particularly in organization-wide knowledge sharing programs, is not a trivial task" ([online]).

The transfer process Denning refers to above constitutes the management part of knowledge management. It is in the management part that ICTs come into their own in KM projects. Although using an ICT system for management creates a whole new set of issues that will need managing often the complexity and share volume of data that needs to be managed will make some form of ICT system the only logical tool choice. That 
said, when it comes to development projects with their often limited budgets, the ICT system does not necessarily need to be that sophisticated or expensive.

Designing the tools and processes in a KM system is an integral stage in any KM project. There are a raft of issues that arise specifically about the tools and processes chosen in any KM system. When designing a KM system for a development project or in a developing country these issues can be further exacerbated. The issues, in relation to development projects, can be broadly expressed by the following: connectivity, collaboration, content and capacity.

\section{Connectivity}

Both the collection and distribution of knowledge are fundamental to a KM system and in many systems will require some form of connectivity. This poses real problems for some development projects where even electricity may be a rare commodity.

Connection to the internet for even the simplest email-based KM system is a real impediment in developing countries as highlighted in the UN Digital Divide Report (UN, 2005). The following table shows the difference in internet, mobile phone, and landline use between different income groups:

\begin{tabular}{|l|c|c|c|}
\hline \multicolumn{1}{|c|}{$\begin{array}{c}\text { Income } \\
\text { groups }\end{array}$} & $\begin{array}{c}\text { Internet users } \\
\text { per } 1,000 \text { people } \\
2003\end{array}$ & $\begin{array}{c}\text { Mobile phones } \\
\text { per } 1,000 \text { people } \\
2003\end{array}$ & $\begin{array}{c}\text { Telephone mainlines } \\
\text { per 1,000 people } \\
2002\end{array}$ \\
\hline High & 366 & 698 & 575 \\
Upper middle & 209 & 355 & 211 \\
Lower middle & 62 & 195 & 144 \\
Low & 16 & 24 & 27 \\
World & 150 & 223 & 176 \\
\hline
\end{tabular}

People living in high-income countries are more than 22 times as likely to use the internet as those living in low-income countries. Where connection to the internet is available even relative poverty ensures that it is all but impossible for the majority of people to afford access to it. The following table shows the cost of internet use for different income groups and then compares it to per capita monthly Gross National Income (GNI):

\begin{tabular}{|c|c|c|c|}
\hline Income group & $\begin{array}{c}\text { Monthly price for 20 } \\
\text { hours of Internet use } \\
\text { US\$ 2003 }\end{array}$ & $\begin{array}{c}\text { Internet price as \% of } \\
\text { monthly GNI per capita } \\
2003\end{array}$ & $\begin{array}{c}\text { Average cost of local } \\
\text { call US\$ per 3 minutes } \\
2002\end{array}$ \\
\hline High & 23.51 & 1.7 & 0.07 \\
Upper middle & 30.27 & 13.3 & 0.09 \\
Lower middle & 31.82 & 32.2 & 0.03 \\
Low & 56.31 & 258.3 & 0.07 \\
World & 36.91 & 88.7 & 0.06 \\
\hline
\end{tabular}


The cost of internet connection in a high-income country is just 1.7 percent of monthly GNI. In even the relatively well-off upper-middle income countries internet access rises abruptly to 13 percent of monthly GNI. In a low-income country access to the internet is a staggering 2.5 times monthly income.

The problem of connectivity can be worked around although any work-around will probably create a less efficient system and quite likely impact on data integrity as well. Information can be collected by hand and delivered to a central location where it is then digitised and stored electronically. A simple survey project is a good example of this whereby people's knowledge is collected, either verbally or in writing, and the information is sent to another location to be managed. The obvious issues here are that people may become disengaged from their own knowledge, the process is much less efficient, and the integrity of the information being collected is put at risk.

The distribution of knowledge is often a key stage in a KM project although, in terms of competitive advantage leveraging, the project may be deliberately designed to channel the distribution to a specific few. When trying to distribute knowledge to many people, or over large geographic areas, connectivity becomes a real issue. In developed countries people have become intimately connected to collective knowledge sharing through the advent of the internet. However, as an estimated 1.6 billion people (Birol, 2007), or 24 percent of the world's population, live in areas without access even to electricity the efficient distribution of digitised knowledge becomes a real conundrum.

Connectivity is one of the major issues of KM systems in development projects. The cost of ICT equipment, where connection is available, creates a significant budgetary expense and the issue of connectivity in areas where no connection exists creates a rather considerable problem indeed.

\section{Collaboration}

The second major theme that creates issues for KM projects is the collaborative nature of KM. The management of information does not necessarily need to involve people any longer. Some very sophisticated databases now exist that deliberately take the potential for human error out of the system's design. As previously discussed, however, $\mathrm{KM}$ is about much more than just the management of information. KM projects seek to extract knowledge from people and, therefore, people become an integral and 
inextricable feature of any $\mathrm{KM}$ project. Complex KM projects may even seek to extract knowledge from diverse groups of people across distant geographical locations involving multiple organisations.

"Since the dawn of human-kind", infers Guzmán (2007) "people have shared knowledge and collaborated with each other to achieve tasks and objectives that were out of their individual reach"(p.68). Guzmán goes on to identify four key concepts relating to collaboration that need to be considered during the design of a KM project.

- Documentation is key

Starting at the beginning the documentation process is identified is being key to a KM project. Documents form the basis of tangible knowledge and documentation is key to telling the story of what happened according to Guzmán.

- Technology needs to serve the knowledge sharing process

Here, Guzmán identifies that technology can easily overwhelm a KM project. She suggests that technology which is, “... something cool but not useful” (p. 75) will be ultimately unhelpful to the project and that key to conducive collaboration is to choose tools that are, "familiar, easy to use, available and useful... [and] it is extremely helpful having technology champions who can provide support" (p. 75).

- Representation of social relationships

The issues that can arise here will be complex as they deal with the interactions of different groups of people. The issues will range, says Guzmán, “... from the place of the individual within the group to the group's relationship with other groups" (p. 75). Managing representation involves balancing the inputs of project participants and the organisations they represent with the level of detail required by the project to ensure the project is not overwhelmed by the most vocal groups.

- Local Context

The fourth key design concept Guzmán discusses is the design of KM projects within the context of the local environment. This concept becomes even more important when working with groups of people from different cultures or from different organisational backgrounds. Using foreign or even ambiguous symbols, imagery and wording will quickly alienate people who are unfamiliar with the type of communication. Guzmán indicates a certain level of trust is required especially for people facing new technologies. "We must take into account the different communication styles of each culture as well as the ways in which they handle trust because these are key elements for collaboration". 


\section{Content}

As previously discussed the nuts and bolts of any KM system involves extracting what it is that people know. The information that is extracted, either raw or repackaged, constitutes the content of the system. Prasad et al. (2005) consider content to be an essential element in KM design:

Capturing and sharing of local content in accordance with the need of the community is an essential step towards people's participation in the developmental process. ICT have a tremendous scope to preserve and share indigenous knowledge, which can enhance people's opportunities and be a major source of empowerment. (p. 128)

A KM project team must make some critical decisions around how the content is to be stored and kept secure, who it belongs to, how it is analysed, to whom and how it will be distributed, if disseminated will it be in full or censored, who is responsible for censorship, does it become intellectual property, and, if so, just whose property is it?

Obviously, the content aspect of a KM project is potentially very contentious. There are a number of precautions that can be incorporated into the design of KM systems to lessen the impact of possible disempowerment due to content ownership issues. These include:

- Trust between the people who share

- Creating horizontal spaces where every participant's opinion is valuable because it's based on his/her experiences; [and]

- Prioritising collective creation (Zúñiga, 2007)

Building elements into the KM system with a specific purpose of creating trust between the project participants, ensuring all opinions are highly valued and allowing the participants to help create the end product will go a long way to mitigating many content issues. A lot of the issues around content are actually issues of content ownership. KM projects seek to extract knowledge from a group of people and it is understandable that this group of people will feel some sort of ownership rights over their knowledge. Guzmán (2007), in the same article mentioned above, offers a fifth key KM project design concept; this one is around ownership. Guzmán believes that, “... if we want participants to see themselves as producers, we should enable them to appropriate the process, to recognize themselves and their ideas in the media used" (pg. 75). 
Ballantyne et al. (2000) reiterate the fact that project participants should be able to retain some form of ownership over the content produced from a KM system:

New ICT's are also well suited to approaches that seek to build joint products and tools with content and resources from many 'owners.' In such cases, ownership need not be handed over, it can be shared and presented in different ways... [project participants] have their own responsibilities, and can manage their own intellectual property. (pg. 4)

Uplifting the knowledge that is being collected and removing it from its source will ensure the project participants feel removed from the end product. KM projects that are open and sensitive to the needs of the participants will actually promote the ownership of knowledge and will allow participants to intervene during the project and add their input into the final outcome. In this way knowledge will flow much more freely and the project content is still owned by the people and groups that it was extracted from.

\section{Capacity}

Capacity is the fourth major issue theme in KM projects. This issue is about the ability of individuals and organisations to deliver. Exactly what will be delivered depends on the KM project but a range of problems arise when it comes to capacity. The sorts of problems that may arise in development projects include: the intellectual ability of project participants, the resources, assets, and technology available, the ability to manage often diverse groups of people and complex processes, organisational governance levels, differing levels of project experience, and the availability of project funding.

Capacity building, or capacity strengthening, is an academic strand of development theory in its own right. USAID describes capacity building very simply as, "a process that improves the ability of a person, group, organization, or system to meet its objectives or to perform better" (2007, [online]). As KM projects tend to be very technical in nature, and often involve groups of people with differing skills, it is prudent to consider the capacity of project participants to meet their objectives. Organisations involved in development projects can be considerably under-resourced and a certain level of capacity strengthening needs to be included as part of the overall KM project design if this is the case. 
If the issue is the capacity of people to deliver on the project then some form of training may need to be incorporated into the project design to increase their ability to interact with the tools and processes of the KM system. If the issue is about organisational capacity then a significant part of the project will be concerned with technological upgrades and new resource allocation (Eade, 2007). Of course these issues add whole dimensions of complexity and potentially substantial cost implications to KM projects. If a need for capacity strengthening is identified it is, therefore, necessary to consider and mitigate those risks during the project conception and planning stages.

The following project workframe (Microsoft, 2007) for an infrastructure intensive project shows the logical places for considering capacity issues in the project life cycle. Here, Microsoft uses the term envisioning for the project conception stage. It is during the envisioning and planning stages that the project team must consider capacity issues as once development of the system begins and can be difficult and expensive to go back to the planning stage to reassess capacity issues:

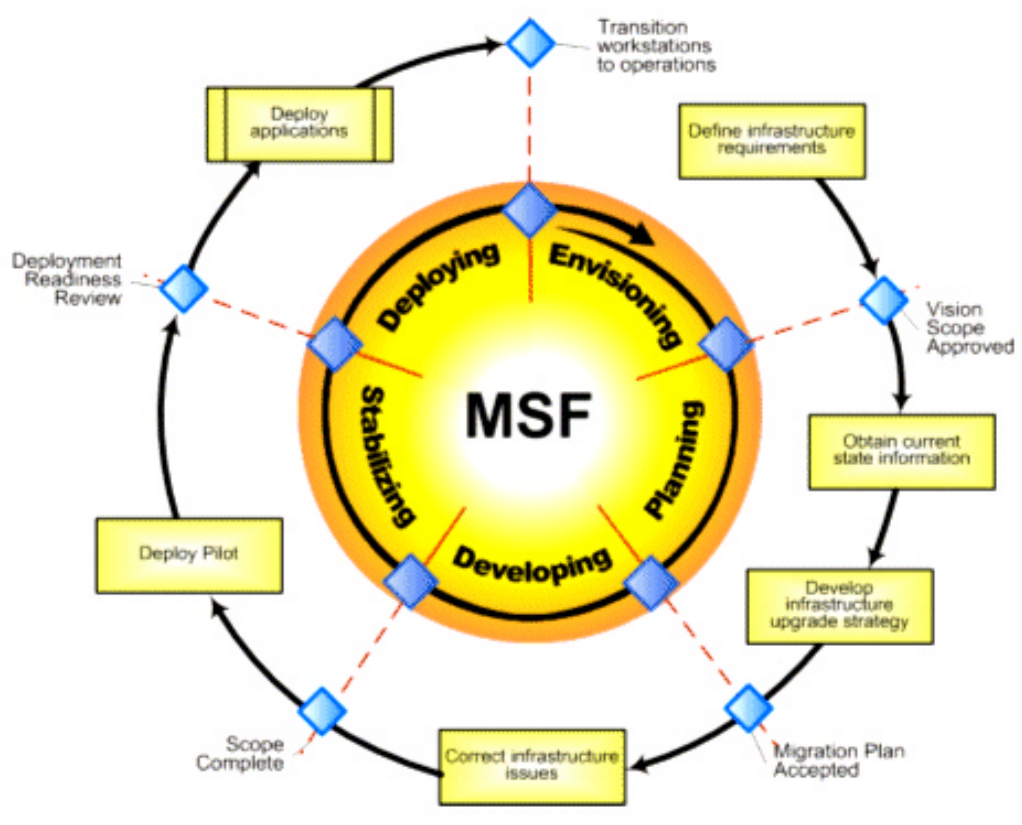

Capacity strengthening creates major cost and management implications in KM projects. It is an area where shortcuts can decrease project costs and timelines considerably. The ability of people to deliver on the project, however, will ultimately decree its success. The most impressive database, one with all the bells and whistles, is, after all, completely redundant if an organisation has no electricity or a project participant has no understanding of computers. 


\section{Practical Applications: Connectivity, collaboration, content and capacity}

The previous section introduced four key issues that require consideration when designing a KM project. Each of these four themes creates different problems at differing points on the project life cycle and there needs to be different strategies developed to overcome each of the problems. Depending on the project, each of these issues separately will have a greater or lesser impact on the project's outcomes and, again depending on the project, will require varying levels of creativity to successfully overcome. As previously discussed designing KM projects in, or for, developing countries will often ensure these issues are further compounded.

This section discusses the four key issues in practical terms by taking a look at four very different KM-based development projects. Although each of the projects deals with all of the key issues, each project, for very different reasons, has one of the four key themes as a major obstacle to overcome. Creative problem-solving is also highlighted by the planners of each of these projects as they come up with quite different strategies to overcome those obstacles.

Connectivity: People First Network - Solomon Islands

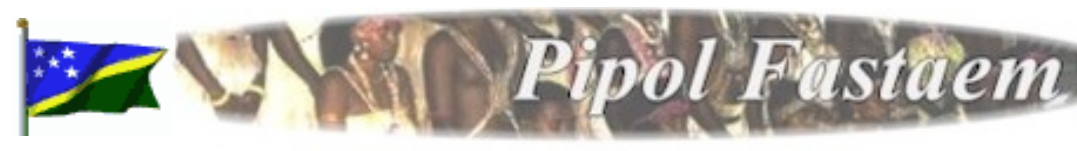

The People First Network (PFnet) project is an extremely successful example in overcoming the issue of connectivity in remote regions. PFnet is a rural networking project in the Solomon Islands that utilises short-wave radio, low-end computers and solar energy to facilitate information flows between an inter-island network of email stations.

The PFnet objectives are to:

- Facilitate point-to-point communications to and from the remote provinces of the Solomon Islands;

- Facilitate rural development and peace-related information flows among all social groups; [and]

- Facilitate the exchange of information between communities and development programmes, NGOs, government offices, the media, businesses and other stakeholders. (PFnet, 2007, [online]) 
The PFnet network now consists of 25 email stations with another five stations funded and planned for deployment throughout the islands. The email stations are all connected to a central hub based in the capital city of Honiara. This base station is a fully functioning internet café servicing the needs of Honiara's residents. Solomon Islanders living in rural areas and on remote islands are connecting to the central hub through their email stations allowing two way flows of information and knowledge to areas where telecommunication infrastructure is basic at best.

The Solomon Islands consists of nearly 1000, mostly undeveloped, islands in the South Pacific that cover an area of some 28,400 square kilometres. Distances between islands make communication logistically difficult. The distance between the western and easternmost islands is some 1,500 kilometres, with the Santa Cruz islands being especially isolated at over 200 kilometres north of the other islands. More than 550,000 residents are spread over more than 100 islands throughout the archipelago with the majority involved in subsistence agriculture and fishing.

The key issue for transferring electronic information to Solomon Islanders living in these remote locations is the lack of telecommunication infrastructure. The PFnet project overcomes this problem by using HF-Radio to send information over long distances where it is received by community supported email stations using renewable energy and a low-cost access model. The success of this KM system has been acknowledged around the world with the PFnet project becoming a finalist in the UNESCO IPDC Rural Communication Prize in 2004 and a finalist in the Stockholm Challenge in 2002 and 2004.

One good example of the success of PFnet in delivering information to the rural community is its collaboration with the UNDPs Regional Rights Resource Team and the Solomon Island's Public Solicitor's Office. This project is helping to facilitate the collection and distribution of legal knowledge to rural areas with direct two-way correspondence to the Office available by email:

$\ldots$ it is long recognized that rural people need better access to legal advice. Most people do not live in the capital, but are often forced to travel there to seek advice on land and resource disputes, family law and for other reasons... The improved communications can now provide an efficient, low cost and relatively secure means of obtaining advice directly in the rural villages. (PFnet, 2007, [online]) 
Knowledge sharing is an important tool in the process of rural development as agricultural techniques can be improved rapidly if farmers have access to good quality, relevant information (Lutz, 1998). One of the key focuses for improving the lives of Solomon Islanders is sustainable rural development. PFnet aims to meet its objectives by “... promoting and facilitating equitable and sustainable rural development and peace building by enabling better information sharing and knowledge building among and across communities" (2007, [online]). The project certainly appears to be headed in this direction.

Collaboration: Ayuda Urbana - Central America-Caribbean

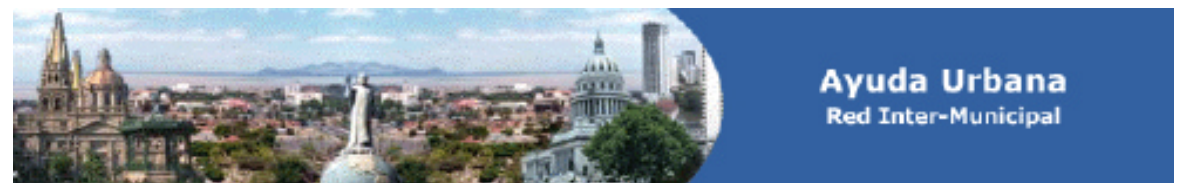

"Collaboration is a key component of knowledge management solutions...

Collaborative solutions empower people to share information anytime, anywhere, enabling groups to work together to achieve synergistic results" (Microsoft, 2007, [online]).

The Ayuda Urbana project is billed as a 'Knowledge Sharing Initiative for Municipal Capacity Strengthening'. The project was originally coordinated by the Union of Capital Cities of Ibero-America (UCCI), an NGO based in South America, and the World Bank. The project partners in Ayuda Urbana come from ten different South American municipalities: Guatemala City, Panama City, Havana, Managua, Mexico City, San Jose, San Salvador, San Juan, Santo Domingo, and Tegucigalpa. Each municipal government provides a number of experts and support staff in eight different thematic policy areas to the project (Ayuda Urbana, 2007). The success of the Ayuda Urbana programme is clearly reliant on the successful collaboration of these diverse groups of people.

Urban development policies in Central America and the Caribbean are critical for millions of people who live in hundreds of crowded cities. The quality of transportation, water and sanitation, social services, and more depends largely on the ability of local urban officials to analyze problems using information from reliable sources and to learn from the experiences of their counterparts in other cities in the region. However, getting relevant and timely information and 
establishing a dialogue with others present difficult challenges.

(World Bank, 2002, p.1)

One of the elements in South American that greatly impedes the availability of timely information is the geography of the region. The Ayuda Urbana project helps to overcome some of the issues of distance and communication costs by utilising the internet as an electronic information and knowledge sharing system and online forum portal. The internet site www.ayudaurbana.com is the central repository for knowledge shared among the municipal government experts.

The KM system in the Ayuda Urbana project begins with participatory workshops based on one of the different policy themes. Each municipal government sends along representatives with expertise in the policy area who exchange their experiences and expertise in that area during the workshop. A facilitator then digitises the knowledge exchanged at the workshop and disseminates this knowledge to the rest of the group using email and the dedicated website.

The website is the key difference in the process of knowledge exchange in this project. Utilised as a knowledge repository, the website offers this diverse group of project participants a dynamic source of information. Project members can continue to add to the information over time and further knowledge sharing can occur in real time. Traditional collaboration for this number of policy makers would not be financially feasible for these municipalities. The website allows the knowledge sharing process to continue in real time for as long as the participants require. Perhaps most importantly, however, the repository is 'owned' by the project members. This open source of knowledge helps to prevent the conflicts, gate-keeping and power struggles that can creep into more traditional collaborative efforts.

The Ayuda Urbana project is a great example of the potential of KM systems to overcome some of the issues associated with collaboration. The project partners are ten municipal governments quite distant from each other and include staff from eight different policy areas. Further, the project has been coordinated by practitioners from the UCCI and the World Bank and is supported financially by the Dutch and UK governments. This successful collaborative effort is underpinned by a KM system that provides these diverse groups of people with relevant knowledge and expertise through a timely and cost-efficient model. 


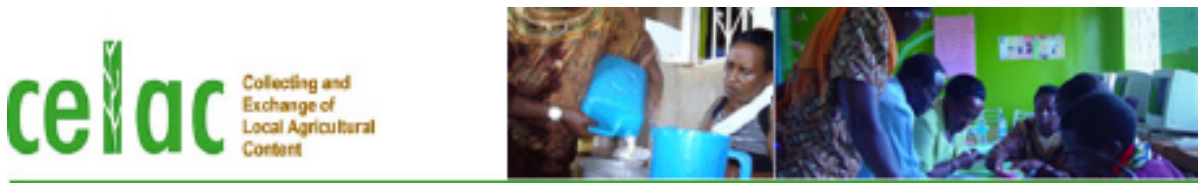

"For years, conventional wisdom among government and the civil society has been that in order to have higher and better farm output, use of modern farming techniques is paramount”, begins Akiiki, “...true as it may sound, the practicality of implementing modern farming techniques in grassroots farming communities is questionable" (2006, p. 68). The Collecting and Exchange of Local Agricultural Content (CELAC) project is a novel KM system working toward solving the development practitioner's perennial problem; that which is conventional and commonsense in the West, seldom translates to practical potential in developing countries.

The CELAC project is a close partnership between government and civil society with the aim of, "improving rural farmers livelihoods and food security through engaging the government and civil society in knowledge sharing and information management of local content using ICTs" (CELAC, 2007, [online]). The emphasis here is on 'local' agricultural content with the idea being to reintroduce local farming practices.

According to the CELAC website a reliance on chemical-based farming practices introduced from the West has negatively impacted on “... the resultant harvests, the air we breathe, our environment, the soil fertility and on human life" (CELAC, 2007, [online]).

The project was born out of a participatory brainstorming session facilitated by the Busoga Rural Open Source and Development Initiative (BROSDI), a local NGO. As well as collecting local content the project also seeks to disseminate that content as far as possible. A number of novel communication tools have been adopted including the CELAC website, on and off-line newsletters written in both English and Lugandan, SMS text messaging, radio call-in programmes and music, dance and drama recorded onto DVDs for use by local NGOs. Local content, produced locally, for local people is a wonderful concept. There are, however, still a number of content-specific issues this project has had to grapple with. These include local content gathering, information hoarding, and literacy levels. 
CELAC 'Knowledge Brokers' are used to hold mini knowledge sharing forums to collect content from local rural farmers, which in turn feeds into the larger regional forums. These forums are held in a participatory format and focus on a targeted crop or livestock type. All of the content collected is uploaded to the CELAC website as well as disseminated through the other channels. Information hoarding, where participants fear loss of a competitive advantage by devolving knowledge, is also managed by the CELAC project team. Sharing as part of the learning process is emphasised at all times and farmers with mass information are strategically picked upon to share their knowledge in the forums. Usually by the end of a forum information flows freely. Finally, literacy levels in Uganda are still relatively low with only around $61 \%$ of females (the predominant sex of rural farmers in Uganda) being literate. Again, the 'Knowledge Brokers' within the villages are tasked with encouraging inter-group adult literacy classes as well as providing training, support and information. This also becomes a perpetual learning process between villages (Akiiki, 2006).

The CELAC project is a very successful example of the management of content in a KM system. "Content is key", writes CELAC in its Annual Report to March 2006, "Uganda's small farmers posses a wealth of knowledge" (2006, pg. 18). CELAC goes on to state that the local content that is extracted through the use of knowledge forums represents both capital, which can be invested in other communities, and a good, which can be traded within a community. "Content is the wealth that CELAC seeks to distribute... This distribution process begins with the documentation of local content... Once documented, a database of knowledge will have been acquired that is of great value to many communities" (2006, pg. 18).

Capacity: Improving Farm Production and Smallholder Farmer Market Awareness - Sri Lanka

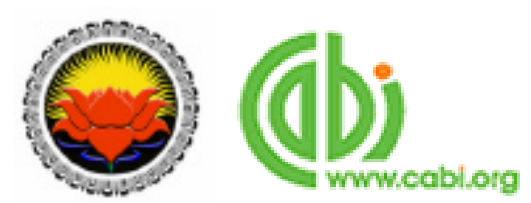

The professional NGO consultancy industry continues to grow globally as ever larger pools of funding are made available around the world and more complex development projects become necessary. Capacity strengthening is often a major focus for these organisations that typically tender for grants from donor countries and then partner with 
grassroots NGOs in the country where the project is based. CAB International (CABI) is one of these organisations. CABI's core work involves scientific research, communication and publishing with a particular focus on microbial services and agricultural and environmental issues.

Sarvodaya is one of Sri Lanka's largest charitable organisations. Founded in 1958, Sarvodaya has grown to now reach 15,000 villages in 34 districts and has 1,500 staff throughout Sri Lanka. Sarvodaya has progressed IT into the rural areas of Sri Lanka utilising 'Telecentres' as points of communication for knowledge sharing and training opportunities for local villagers. Based within a district centre each Telecentre services over 300 villages. There are thirteen Telecentres currently functioning with a further thirty-four planned. The role of the Telecentres is to help bridge the digital divide:

\footnotetext{
IT has failed to travel to rural areas in Sri Lanka and its far-reaching benefits have been limited to the urban communities and the richer classes of the island. Rural folk who live in remote villages have been deprived of the boons that are brought through the expansion of this knowledge. (Sarvodaya, 2007, [online])
}

While the Telecentres are very effective at introducing new knowledge into the rural areas of Sri Lanka they have not, according to CABI, greatly increased villagers' access to farming information. Clearly there is a capacity issue here. Sarvodaya have good quality infrastructure installed, local collaboration initiatives are instigated, connections to the internet are set up and a large pool of relevant content is available. To offer access to the type of technical information needed Sarvodaya needed to partner with another organisation that can provide new skills and knowledge to help build the capacity of Sarvodaya's Telecentres to deliver to the community.

As a world renowned scientific information provider and an organisation with many years of experience working in developing countries, $\mathrm{CABI}$ was well placed to fulfil the capacity needs of the Telecentres. CABI suggests that although Sri Lanka has been growing quite rapidly the country's agricultural GDP has only been growing at a rate of $1.6 \%$ per annum (CABI, 2007). Both CABI and Sarvodaya believe that improving agriculture in Sri Lanka could greatly reduce hunger and poverty and that improvements can be made through the provision of:

...a platform for sharing agricultural knowledge and experiences within the Telecentres that already exist. In this way, CABI aims to 
The Telecentres, enhanced with CABIs knowledge and resources, are now known as Agri-clinics. The Agri-clinics are a great example of a KM project where one organisation has collaborated with another to build its capacity to deliver further benefits for the communities it serves.

The four projects outlined above are very successful examples of knowledge management for development. Managing knowledge for development is a positive and productive enterprise but this thesis is concerned with something else. This thesis is concerned with managing knowledge for growth. The next chapter progresses the discussion of managing knowledge but adds the new dimension of competitive advantage to the discussion. More specifically it discusses utilising $\mathrm{KM}$ to create a competitive advantage and leveraging this competitive advantage for growth. This discussion is framed within the context of the community and development sectors and, as pointed out in Chapter One, is a discussion that is relatively novel to the academic study of KM. 


\title{
Chapter Four - Managing Knowledge for Competitive Advantage
}

\author{
One of the hallmarks of the information age is that the new currency \\ of business is information or knowledge. The way in which that \\ knowledge is managed can ultimately determine the success or \\ failure of any enterprise. Digital technology can play a major role in \\ increasing the speed and effectiveness of information flow and in \\ breaking down the barriers to successful knowledge sharing. In \\ addition, it's one of the ways that businesses can gain competitive \\ advantage. (Microsoft, 2007, [online])
}

When Brinkley discussed gaining a competitive advantage by exploiting the unique properties of knowledge in the opening quote he was specifically referring to the private sector. Here, Microsoft also refers to gaining a competitive advantage through the management of knowledge but uses the term 'enterprise', which could also include NGOs. This chapter will go further still and discuss the opportunities available in leveraging competitive advantage specifically in relation to NGOs. This section considers the thesis that NGOs should not just be considering competitive advantage but, in fact, should learn to embrace the concept and to incorporate it in all its decision making processes. It will look at this idea in terms of KM theory framed within an economic argument.

To begin with, Competitive Advantage in Relation to Knowledge Management briefly outlines what competitive advantage is and then considers this in relation to ICT and $\mathrm{KM}$. A critical assessment of the current technology climate in the community sector in Aotearoa-New Zealand is also presented. In Leveraging Competitive Advantage in the NGO Sector a number of facts regarding the community sector are described.

Competitive advantage, again in relation to $\mathrm{KM}$, is then considered in terms of current NGO practice in relation to these facts. The discussions are grouped into the headings Funding, Resources, Specialisation or Utilisation, and Grow or Die.

\section{Competitive Advantage and ICT}

In terms of economic theory competitive advantage occurs when an organisation is able to deliver a product cheaper, or offer a service with more benefits, than its competition. This describes two types of competitive advantage that Michael Porter (1985) identified, namely 'cost advantage' and 'differentiation advantage'. Although achieving 
competitive cost advantage is also just as relevant for NGOs as private companies it is the competitive differentiation advantage that will be explored further.

To achieve a competitive differentiation advantage the organisation must look internally to exploit those facets of the organisation that make it truly different than other organisations in the same industry. One such definition of this type of strategy is offered by Markintell.com (2007), an online market research resource, “... competitive advantage is gained by exploiting the unique blend of activities, assets, attributes, market conditions, and relationships that differentiates an organization from its competitors" ([online]). ICTs now offer organisations a whole new set of tools enabling them to exploit these more 'intangible' production factors.

Porter and Miller were associating ICT with competitive advantage as far back as 1985 . They were certainly correct in conceiving the significance of the ability of ICTs to give firms a new edge in competitiveness. They were also correct in predicting that companies unable or unwilling to respond to the use of ICTs would be left holding a new shape of ball, designed by their competition, with no idea how to bounce it:

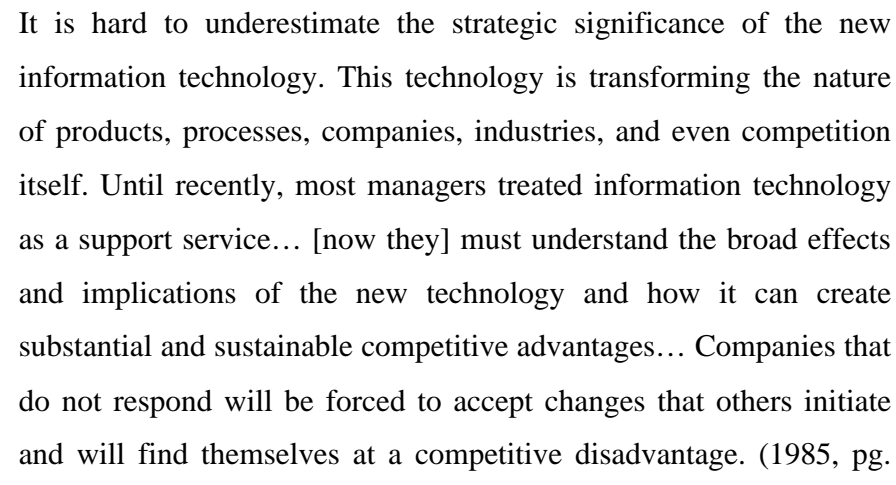

Surprisingly, ICT usage by NGOs in Aotearoa-New Zealand is still considerably low. The use of email as a communication tool has become much more wide-spread and many NGOs now tend to have at least one computer workstation in their office but the overall picture is one of a remarkably slow uptake and transition to technology in the NGO sector. The NZFFBS, for instance, is able to communicate with around $90 \%$ of its members by email (although some of these addresses are personal and accessed through a home computer) and it estimates only around $75 \%$ of its members have direct access to the internet in their offices (NZFFBS, 2007). Electronic record keeping, access to relevant data and resources, reporting and analysis functions, communication, data 
management and general office administration processes are all seriously constrained in this environment.

In 2001 (after the spectacular dot-com crash) Porter was perhaps a little more careful in his approach and language but was still associating the use of technology with gaining a competitive advantage. In this article Porter explicitly points out that just having an internet presence will not afford an organisation an advantage but infers that the use of ICT tools, such as the internet, together with an effective strategy will:

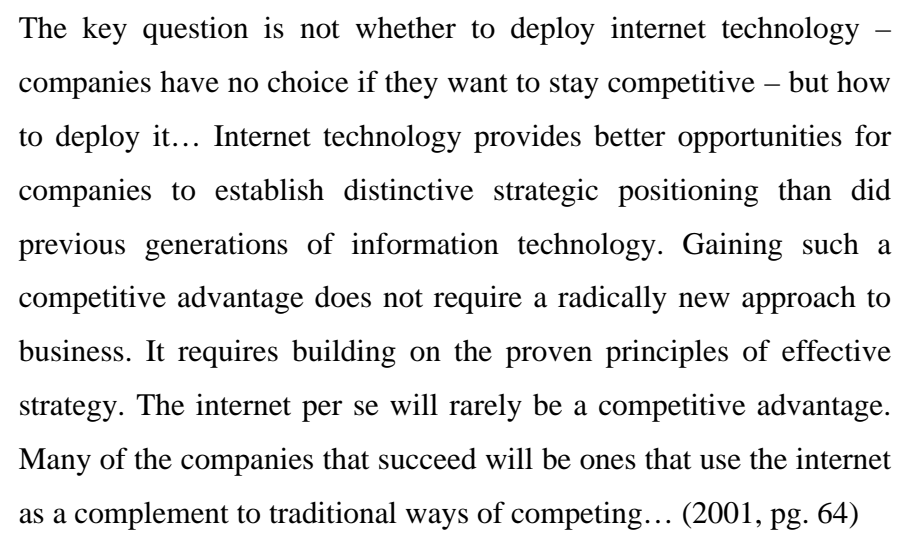

As equally lamentable as the lack of technology usage, there are still many NGOs in Aotearoa-New Zealand that have limited or no internet presence; the same being true for many private companies (Statistics New Zealand estimated only around $36 \%$ of enterprises operated a web site in 2001). Some 17 years have now passed since Tim Berners-Lee finished shaping the World Wide Web and these organisations appear to have completely overlooked the value of an internet presence. Certainly there are costs involved and technical knowledge that needs to be utilised but in a country with one of the highest penetrations of internet usage in the developed world (74.9 percent penetration according to Internetworldstats.com in 2007) these organisations show a real lack of strategic thinking and are putting themselves at a clear disadvantage to their competitors.

For far too many NGOs ICT is simply seen as a tool to increase the efficiency of day-today processes. This is seen in the fact that ICT is rarely at the top of a governance committee's agenda (Widmer, 1993; Harris, 1996; and Conforth 2002) and this means that ICTs are not being discussed in relation to strategic planning in NGOs. It could be argued, however, that just because using ICTs to gain competitive advantage is at the forefront of thinking in successful private firms that this does not necessarily mean it is 
appropriate for NGOs. Although there may be some truth to that argument the purpose of this thesis is to show that developing technology-led, strategy-based thinking in NGOs is imperative. The following section shows how leveraging competitive advantage can be the difference between success and failure for NGOs and how KM strategies can help toward achieving this advantage.

\section{Leveraging Competitive Advantage in the NGO Sector}

The following are fact. There is a finite pool of funding available in the world for the NGO sector. Most NGOs are very small organisations run by very few, albeit highly experienced, individuals. Most NGOs work in niche sectors and tend to specialise in the area that they represent and a considerable amount of energy is expended working out just exactly what it is that they 'do'. Some NGOs grow, some stagnate, and others shrink. Some NGOs end up 'wound up' and a wound up NGO has the same status as a bankrupt private company; it is about as 'dead' as a legal entity can be.

With the above facts in mind, this section considers four main arguments as to why competitive advantage is so important in the NGO sector and how it can be leveraged for organisational growth.

\section{Funding - Chasing the money-go-round}

For many NGOs chasing funding is a major part of their work with considerable resource put into planning and executing funding strategies (Sargeant \& Jay, 2004). As there is only a limited amount of funding available to the NGO sector a very competitive environment exists whereby the more competitive an organisation is the larger the slice of the funding pie they tend to receive.

The funds secured from chasing government grants, philanthropic funding, community trust monies, corporate sponsorship, public and private donations, bequests, etc. are all, in some part, determined by the ability of an NGO to differentiate itself from the competition. If an NGO enjoys a monopoly position then that could be exploited for growth but most NGOs now find themselves competing directly with many other organisations selling similar services to a relatively small donor target market (at least in Aotearoa-New Zealand). 
An online internet search illustrates this problem quite clearly. A search for the term 'cancer' in pages from Aotearoa-New Zealand finds the following NGOs in eight of the top 10 results: Cancer Society, Child Cancer Foundation, Prostate Cancer Foundation, Breast Cancer New Zealand, Auckland Cancer Society, Cancer Society Wellington Division, Breast Cancer Research Trust and the Breast Cancer Network. Although each of these NGOs are worthy in their own right of having their full work programmes funded there is still only a finite pool of funding available to them all and clearly the competition in Aotearoa-New Zealand is fierce.

In such a competitive environment achieving a differentiation advantage will be key to establishing a long and prosperous ride on the money-go-round. This is due to the majority of funding available being that of a contestable nature. Certainly some organisations are fortunate enough to have bequests or legislated funding available to them but the majority of funding available in Aotearoa-New Zealand is contestable.

The ability to secure funding can simply come down to exhibiting a point of difference from your competition. In such a hotly contested environment, the ability to clearly define your organisation's work and show its success through good-quality information is key to securing the limited funding available. In an industry where a $\$ 25,000$ grant is secured with a four-page application form and two-page cover letter having accurate and timely information to hand is essential. An effective KM system offers this and, therefore, must be an element of all NGOs' fundraising and growth strategies.

\section{Resources - He tangata, he tangata, he tangata}

Although many NGOs now sell products, the lion's share of revenue still comes from selling services (Green \& Haines, 2002); that is, NGOs sell the experience and abilities of their people. A well voiced Maori whakatoaki (proverb) that is often used in relation to not-for-profit organisations in Aotearoa-New Zealand states, 'he tangata, he tangata, he tangata' or 'it is people, it is people, it is people'. The strength of this proverb is in its simplicity and is well recognised throughout the NGO community. In relation to NGOs, the whakatoaki suggests that non-profit organisations owe their beginnings to people, their ongoing success to the abilities of people and fundamentally exist for the people. 
The human resource, then, is a considerably important asset available to NGOs. Most NGOs have a staff of highly experienced and very passionate people. Often the accumulated knowledge of these people is extraordinarily rich. The combined experience of the NZFFBS National Board, for instance, totals well over 100 years of practical budgeting experience. Unfortunately, however, unless this depth of knowledge is somehow extracted it can leave the organisation at the precise moment as the people do; this is where KM theory can play a crucial role.

Carrillo (2002) believes that the time has come for KM theory to be applied to NGOs and other 'human organisations':

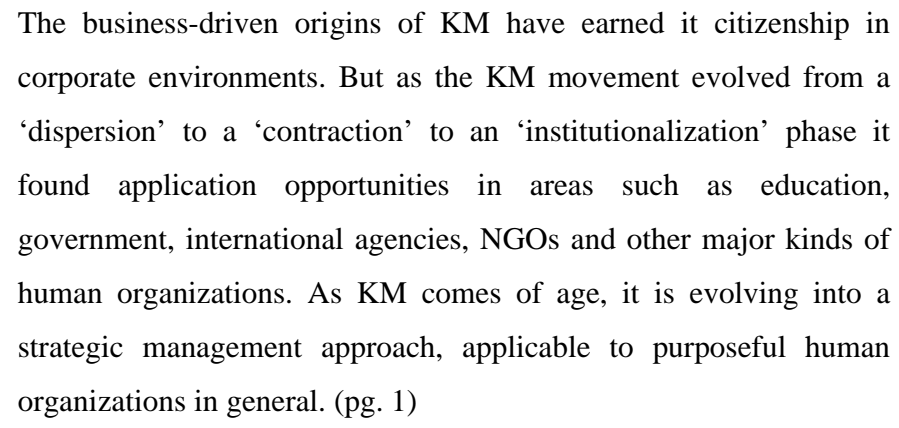

Carrillo's assertion that KM is evolving into a strategic management approach is a vital clue as to where KM belongs in the NGO's thinking space. Strategic management involves analysing historical trends to plan for future events and a KM system can offer an organisation the crucial information it needs to plan for a long and prosperous existence. It is the people within the organisation from which this information will ultimately come and this often overlooked resource demands much closer consideration.

In order to achieve the long and prosperous existence mentioned above organisations, including NGOs, will need to remain competitive over the long term. A differentiation advantage will certainly help an organisation achieve that level of competitiveness and it is the utilisation of knowledge from its human resources that can help an organisation to differentiate itself from the competition. A well managed KM system, therefore, can enable NGOs to leverage the knowledge from their human assets to grow and remain competitive over the long term. 
Specialisation or Utilisation - Creating sustainable competitive advantage

It is certainly true that many NGOs are extremely good at what they do and there is a very good reason for this being the case. Most NGOs offer specialist services in rather niche areas of the economy. As many NGOs owe their humble beginnings to a handful of talented individuals that decide to change some 'thing' (be it the degradation of the environment of the Ring-tailed Lemur in Madagascar or the reduction of stigma around dyslexia in schools in Otago) it seems logical that NGOs tend to become specialist organisations.

Further, NGOs tend to expend considerable amounts of energy working out just what it is that they 'do' in their respective niche areas in order that they can clearly communicate this to their stakeholders, funders and supporters. This is evidenced in the creation of organisation mission statements, production of resources outlining organisational work programmes and the amount of time non-profit committees spend analysing and learning how to communicate their 'brand'. "While [the board's] fiduciary function may be organisation oversight, their greatest value comes from opening doors to opportunities and from evangelising and living your brand" (LePla et al., 2003, pg. 255). In their book Brand Driven LePla et al. argue that clearly defining and communicating what an organisation does will ultimately lead to increased revenue. In effect, LePla et al. are prescribing a specialisation path to growth.

Through developing a specialist service offering, creating brand awareness around that offering and focusing on delivering that service better than another organisation NGOs are embracing the concept of competitive advantage whether they realise it or not. Unfortunately, without first achieving a differentiation advantage all of this specialisation work may come to nought. "Specialization in a niche for a business helps ensure the sustainability of the competitive advantage" states Jackson (2006, pg. 33). He asserts that a competitive advantage can only be sustained if other organisations cannot copy or deliver the same thing. Two recent, and rather drastic, examples of the inability to sustain an advantage occurred in Aotearoa-New Zealand in 2007. The first involved the New Zealand Plunket Society and its specialist phone line service and the second a local charity in Porirua that offered an employment service specifically targeted to older people. 
In the case of PlunketLine, Plunket's free phone service offering, although it was specialised in that only registered nurses could answer calls and the service was targeted to parents with babies and small children, it was not, unfortunately, different.

McKesson, a large, multi-national healthcare provider specialising in delivering telecommunication services used its cost advantage to win the PlunketLine contract from the Aotearoa-New Zealand government (TVNZ, 2008). In the second example Mature Employment Support Services also offered a specialist service, in this case it was an employment service specifically targeted toward middle-aged and older people re-entering the workforce. Although this might have seemed a novel idea, had the organisation done some market research it would have discovered that the Salvation Army offered an identical and much more sophisticated service. As in the first example the much larger organisation was able to replicate its successful business model to capture a cost advantage and win the local government contract (CityLife Porirua, 2008). The first example meant the loss of a potentially lucrative work programme and in the second the smaller organisation had to be wound-up.

With too much emphasis on specialisation and too little on utilisation an NGO leaves itself wide open to competition. Once again, therefore, the utilisation of an NGOs human resources to develop a competitive advantage through differentiation should be first and foremost in the minds of NGO decision makers.

\section{Grow or Die - Employing transformation theory in the NGO sector}

Dr. George Land's seminal work published in 1973, Grow or Die, is as equally relevant for civil society organisations as it is for private ones. The three phases in organisational evolution: experimentation, growth and reinvention are at play in non-profits in just the same way as they are in private firms. In fact, a new grass-roots NGO displays many similar characteristics as a new start-up firm including passion, innovation, drive, vision, etc. with perhaps the main difference being only that the latter strives for profits while the former strives for social change.

Once the initial experimentation phase is over, usually either characterised by success or failure, the growth stage comes with relative ease. In the case of the NGO, proof of its success should increase its ability to attract further funding, more resources and a larger workforce. It is the reinvention phase that NGOs may struggle with and this is 
characterised firstly by organisational stagnation, which in some ways is actually worse than Dr. Land's ultimate outcome.

A stagnated NGO is doing what it has always done (and getting what it has always got), its staff have lost their innovative edge and are just 'going through the motions' and staff turnover will inevitably increase, the customer and stakeholder base will be static or even in a slow decline, and the organisation may be viewed cynically (both internally and externally) especially if its funding levels are stable or increasing. An NGO may stumble through this phase for many years and may still even be delivering a justified service but it will no longer be able to attract the funding, resources and personnel it did while in its earlier experimentation and growth phase. Eventually the likely outcome, unless something or someone changes within the organisation, is that the funding levels will fall away and a decision will be made to wind-up. The process of change that is needed characterises the third phase of reinvention or transformation.

Transformation is all about the process of change. Managing change successfully will lead to organisational growth through innovation and stimulation; that is, reinventing the product or service delivered (or indeed the entire organisation) and stimulating the people involved to move forward in a new direction. Spencer Johnson (1998) discusses the process of change in his quirky book Who Moved the Cheese. The cheese, in the case of the stagnated NGO, is its product or service offering:

- Change happens: They keep moving the cheese.

- Anticipate change: Get ready for the cheese to move.

- Monitor change: Smell the cheese often so you know when it is getting old.

- Adapt to change quickly: The quicker you let go of old cheese, the sooner you can enjoy new cheese.

- Change: Move with the cheese.

- Enjoy change! Savour the adventure and the taste of new cheese!

- Be ready to change quickly-again and again: They keep moving the cheese.

A well-functioning KM system will greatly enhance any change management process by ensuring the monitoring part of the process occurs effectively. By successfully monitoring change through a KM system the NGO's decision makers will also be in a better position to anticipate and plan for change. Quality change planning, which is also enhanced by a KM system, will also help to ensure that the adaptation part of the 
process occurs more smoothly and this will inevitably help toward the sixth goal in the process, that is, to enjoy change.

Thus far, this thesis has considered the concept of competitive advantage in relation to the development sector, discussed four successful KM projects that are developing such an advantage for the organisations concerned and outlined the environment in AotearoaNew Zealand that was conducive to creating a KM project to measure the effects of government policy. The next chapter details this KM project. The project is known as the Client Voices pilot project. The next chapter considers this project in considerable detail and Chapter Six then analyses this information and offers a number of recommendations for future KM projects in the community sector. 


\section{Chapter Five - The Client Voices Pilot}

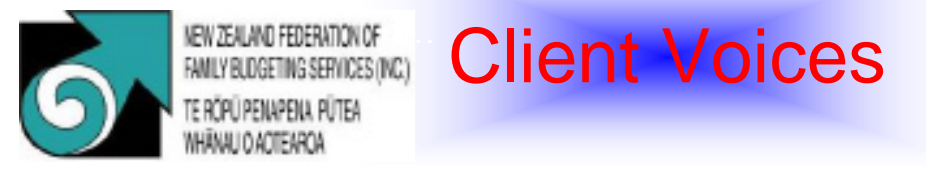

For consumers living on less than US\$1 or US\$2 a day, our starting point is to end poverty. Such consumers need to live in economies where sustainable development to reduce poverty is realistically promoted... Included in the structural changes Consumers International envisions, should be a system for the accreditation of [NGOs], as in the United Nations, so consumer voices can be heard as a matter of right, not merely because of an occasional invitation. (Asia Pacific Consumer, 2008, p. 26)

The premise of the Client Voices project is that consumer voices should be heard as a matter of right but that social and structural conditions exist that permit this from being a reality. The purpose of the Client Voices project is for the NZFFBS to become an authoritative voice to effect positive change for consumers. If the NZFFBS can become an authoritative voice then perhaps it can speak loudly enough and the social and structural conditions that exist can be broken down.

This chapter discusses the fieldwork component of the Client Voices pilot project; the potential preliminary to the Client Voices project. First, in Methodology, the pilot project methodology is discussed in some detail. Nine sections have been used to breakdown the methodology into specific project work areas. The second section, Fieldwork, then explores each of these areas in further detail under 13 section headers and describes the work undertaken at each point during the project.

\section{Methodology}

The purpose of the Client Voices project was for the NZFFBS to become an authoritative voice able to effect positive change for consumers in the financial market. A virtual network of budget services exchanging information through improved electronic collection mechanisms would be the catalyst to allow this to happen.

The Client Voices pilot project, however, had slightly different objectives. Although the overall goal above is exactly where the project participants were heading the pilot 
project had four objectives it needed to meet to prove that the Client Voices project would be both successful and sustainable in the long term. Further, twelve project goals were established that fell under one of the four objectives.

\section{Objectives and Goals}

The first objective, governance and process development, took a total of six months to complete and included the following goals: member consultation, workframe development, participatory workshop, form development and the governance process. The second objective also took six months to complete and had just one goal, which was the development of the Client Voices database. The third objective, training, testing and rollout, had five goals needing completion including writing the service contracts, fundraising, training, testing and rollout; all up, this objective would also take six months to complete. The fourth and final objective had one goal, which was monitoring and reviewing the project. Four weeks were originally allowed for this last objective but circumstances beyond control meant that the project timeline slipped considerably toward the end of the project and this date was extended.

\section{Project Participants}

The pilot project was managed by the NZFFBS's Information \& Policy Officer and overseen by the NZFFBS's Chief Executive Officer both of whom reported directly to the NZFFBS National Board. The project partners included the NZFFBS, Whangarei Budget Service, Manawatu Home Budget Service, The Porirua Budget Service, Lower Hut CAB Budget Service, Timaru Budget Advisory Trust and Dunedin Budget Service. Each of the budget services had two staff working part-time on the project; a database administrator responsible for the data input and project administration and the service Coordinator/Manager who was responsible for project outcomes at the local level.

\section{Technical Skill Requirements}

Although the pilot project methodology was relatively simple it did require a certain level of technical skill as the choice was made early on to design the database in-house. Also, even though the actual database creation was out-sourced to a developer the NZFFBS had a high degree of ongoing input into the development process to ensure the database met all of the required standards. Finally, the NZFFBS also took on the role of 'helpdesk' to the six budget services during the testing and rollout stages. Fortunately, the NZFFBS had the skills in-house to do all of this work and had a long-standing 
relationship with a programmer who allowed a hands-on development process to take place. Unfortunately, this meant that the project was very reliant on just two people; a substantial risk that would become very apparent.

\section{Governance and Process Development}

The single most important aspect of the methodology was the governance and process development. It was established that to collect better information an electronic information collection process needed to be created. This immediately meant that a high-degree of change was going to be inevitable. Budget services affiliated to the NZFFBS are undergoing a slow change toward technology and range from those that have custom-made client databases running on modern, networked computers to those that use paper filing systems.

Buy-in from the NZFFBS membership was going to be of the utmost importance to ensure that a potentially large degree of change could be successfully managed. As well as the inevitable technological upgrade a number of service forms and their associated processes would also be changed. These forms constitute the basis of budget advice delivery and had not been changed for a number of years. Early on in the project it was identified that changes should be made to the forms as the database would be designed around the forms and fundamental changes to the database later on would be costly. Changing budget advice processes is a governance issue for the NZFFBS and the National Board had to formally accept and adopt the new forms.

\section{The Client Voices Database}

Building the Client Voices database was the most time-consuming aspect of the project. This part of the project could potentially have taken much longer than it did. Fortunately, the NZFFBS already had a client management database built for its services some years prior. Although this database was outdated its design was fundamentally sound and this design was used as the foundations on which the Client Voices database was built.

The database was written in Clarion 5. This is a very robust and flexible programme that the NZFFBS's preferred choice of programme developer specialised in. Many other programmes could probably have been used to create just as robust a KM system but as 
Clarion had already been well tested in the NZFFBS's environment it was decided not to spend time researching other programmes.

\section{Training, Testing and Rollout}

The training was originally planned as a one-day workshop in five main centres around the country (each service being funded to send two people to a workshop closest to them). As the pilot project ended up working with just six services a one-to-one training session was organised that took place at the budget service on their own equipment in a more informal setting. This method offered a number of benefits.

The smaller number of services involved in the pilot also allowed the testing process to occur more informally. With just seven people interacting the NZFFBS was able to run its helpdesk function over the phone and was also able to send out a staff member to two of the closer services on a number of occasions.

The rollout phase occurred much later than originally planned for, due to slippage in the development time. The rollout of a completed database was intended to occur some time after the third month of testing; it ended up happening in the sixth month. A number of techniques were trialled to install the new database and this provided an ultimately successful learning point for further rollout of the database.

\section{Monitoring and Review}

Monitoring occurred on a weekly basis recording the flow of data, interaction between the project participants and the ongoing development of the KM system. The training, testing and rollout phases were also closely monitored in order to develop a bestpractice manual for later rollout of the database. The project was reported to the NZFFBS National Board on three occasions during the duration of the project and the ongoing monitoring was used to write project update reports that were delivered to the National Board and also used to report back to the NZFFBS membership.

A full eighteen month review of the project was planned to occur during the eight weeks following a full six months of data gathering. The slippage in development time moved this date out to twelve weeks, which did allow the project team extra time to work on a final report. Although the final report was dependent on full data streams being delivered the actual data set was not the focus of the report. The goal of the pilot project 
was to develop a model that could be used to rollout the KM system throughout the entire network of NZFFBS budget services and this was the major focus of this final review.

\section{Timeline}

The project timeline was referred to as the 'Workplan' (Appendix iv). The Workplan mapped out the major project tasks from July 2006 to July 2007. It was created during the pre-planning phase of the project so a number of tasks were included as pre-July 2006 for continuity. Major project activities were colour-coded and entered into the Workplan on close-to-approximate completion dates.

\section{Funding and Budget}

The Client Voices Funding Plan and Budget (Appendix iii) was developed and updated a number of times as the project was developed and resources were rationalised. The final plan and budget that was signed off by the NZFFBS National Board came to a total of $\$ 157,868.75$. It included four major funders and a shortfall (to be covered from reserves) of $\$ 12,254.75$. It also included a pending figure of $\$ 68,655.00$ from the Community Partnership fund that would be ultimately declined.

\section{Fieldwork}

\section{Member Consultation}

One of the first, and arguably most important, tasks that occurred was the member consultation process. Until this point only the NZFFBS national office staff and staff from MCA had discussed the project in any detail. From those discussions it was obvious that what was required would affect the entire organisation and that a process of member consultation to create 'buy-in' to the concept was needed.

It was decided to send both the NZZFBS Chief Executive Officer and President to each of seven regional meetings around the country to deliver a project presentation and gauge the overall impression from the organisation.

The presentation was created by the project team and the consultation meetings occurred in August 2006. There were more than 330 delegates at the seven meetings that represented over a third of the NZFFBS membership. 
There was an overwhelmingly positive response in favour of moving ahead with the project and this feedback allowed the project to go to the next stage.

\section{Workframe Development}

As soon as the positive feedback from the member consultation had been communicated to the project team the project conceptualisation phase began. What was required in this regard was to take the overall goal of the project that the membership had agreed on and turn it into a number of processes that would be required to achieve it.

This concept, which was known as the Workframe, would be used to capture the ideas that were still inside people's heads at this point and to turn them into a graphical representation of what the process would look like.

The Project Workframe (Appendix i) was firstly used in the presentation to the membership at its Annual General Meeting and then used by the project team as a point of focus going forward.

Again, at the AGM there was a positive response to the project from the members and a general consensus of moving ahead as soon as possible.

\section{Participatory Workshop}

The participatory workshop was a fundamental task in the project design. The workshop was fairly intensive and conducted over one full day in Wellington. The people involved in the workshop represented:

- Budget advisers

- Service Coordinators/Managers

- Regional and District Representatives

- Database administrators; and

- NZFFBS staff

The workshop was a loosely structured brainstorming session based around three integral elements of the database:

- Form development

- Feedback on the limitations of the existing database; and

- Database task 'wish list' to be incorporated in the new database 
Extensive notes were created from feedback on the existing NZFFBS forms. From this feedback it was very clear that there were a number of obvious weaknesses in the existing forms and this knowledge was used to push for the change in procedures that would be required in order to redesign the forms.

The sessions devoted to the old and new database were more conceptual than the form development but the feedback was just as important. The brainstorming notes here were also collated and formed the basis of what would become the database task list from which the project specification would be written.

\section{Form Development}

One of the more significant elements of this project was the redevelopment and creation of the forms that were required to collect the data. The reason this was so significant is that these forms would become part of the 'Federation Process' of delivering budget advice and would, therefore, be used by every single NZFFBS budget adviser throughout Aotearoa-New Zealand.

The extensive notes made on the form development during the participatory workshop session were used to design and recreate the following forms:

- NZFFBS Budget Worksheet

- NZFFBS Debt Schedule

- NZFFBS Client Case Notes; and

- NZFFBS Initial Intake Form

As the first two of these forms already existed a similar layout was able to be used. The second two forms did not exist and had to be developed. Microsoft Excel was used to create all of the forms as the cell layout in Excel lends itself to designing forms based around tables. Each form was then saved in Adobe PDF format for printing.

These forms, which are used during the budget advice process, were then used to create a framework from which the database would be created. 


\section{Governance Process}

The governance process for this project was robust but very straight forward. The NZFFBS National Board asserted that any aspect of the project that would affect policy would need to be presented to the Board before going ahead and that any aspect that would affect practice would be scrutinized, first by the Board, and then by the District Representatives.

This could have created a number of issues for the project team for two reasons. As some people within these groups were not computer literate the technological concepts needed to be very clearly explained. Also, a number of procedural changes would be necessary for this project to work, some of which had not changed for many years.

In practice, however, both of these governance groups were very supportive of the project. The project plans were certainly scrutinized in detail but the overall goal was well understood by everyone concerned and there was a general openness to the idea of change. Once the project was up and running regular project reports were also presented at each of the National Board and District Representative meetings.

\section{Fundraising}

The fundraising efforts were the single biggest headache for the project team. After signing a Memorandum of Understanding with the Ministry of Consumer Affairs and securing two rounds of funding from the Ministry the NZFFBS negotiated an 'in-kind' contribution from Telecom New Zealand for free broadband connections, modems and 12 month subscriptions for up to 25 services. The project team were successful in negotiating with the database developer a substantially reduced software license fee as a further in-kind donation. This together with the $\$ 35,000$ already raised left the project in a financially stable position as the team made its application to the Government's Digital Strategy Community Partnership fund.

As discussed earlier, the NZFFBS was unsuccessful in two consecutive rounds of applications to this fund. This was almost a showstopper for the project; one which forced the project team to revise the original plan and work on a pilot option instead.

The project team have tried to 'sell' this concept to a number of philanthropic trusts and government departments with little success to date. This leaves the ongoing 
sustainability of the project in a rather precarious position. The next step is to use the six month datasets from the six pilot services to try and sell the project concept with hard data as opposed to trying to sell a 'blue-sky' ideal.

\section{Database Development}

The database development constituted one of the largest pieces of work in the project. Although a developer was contracted to write the programme the NZFFBS project team had a very hands-on role in both the design and development processes to ensure the database could manage all of the tasks it needed to.

It was decided early on to create a 'project specification' (spec) document (Appendix v) to capture those tasks that the project team had constructed (which, in turn, came from the brainstorming notes collected during the participatory workshop). More specifically the spec outlined the end-user groups involved:

- Budget service Coordinator/Manager

- Budget adviser

- Database administrator; and

- NZFFBS Inc project team

Under each of these end-user groups the spec detailed the tasks that each group would require the database to perform, respectively these included:

- Service details and notes

- Staff positions, training records, appraisals, and notes

- Adviser worklogs (multiple adviser view)

- Report views

- Client records and client details

- Client budget worksheets, debt schedules, and case notes

- Adviser worklogs (single adviser view)

- Data export tool

- Confidentiality and data protection issues

- Credit contract screen

- System tools; and

- Data dump process and documents 
A particular spec methodology type was chosen to work from that involved creating an 'application flowchart' to visually explain the database processes. This methodology was borrowed from joelonsoftware.com. Joel Spolsky hosts a light hearted yet educational website about software creation and has been writing articles for the site since March 2000. The final spec design was based on what Spolsky calls a 'functional specification', which, “describes how a product will work from the user's perspective. It doesn't care how the thing is implemented. It talks about features. It specifies screens, menus, dialogues and so on" (Spolsky, 2000, [online]). The second type of spec described is a 'technical specification'. As the new database was using the existing NZFFBS database as a model aspects such as programming language, data structure, data relationships and modelling, etc. were not required.

The example application flowchart offered by Spolsky was actually too brief to use in this project. The example is an over-simplified version of how a graphic representation of the actual product (in this case a website) can be used to create a 'storyboard':

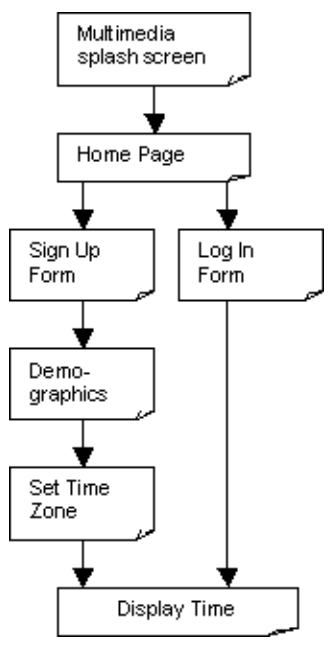

(Spolsky, 2000, [online])

This concept was taken a step further by creating a 'key' of different graphical shapes to represent the different views and levels of navigation that were necessary in the much more complex Client Voices database:

Key
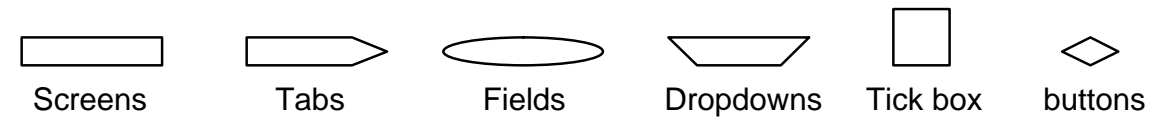

(Appendix v) 
The key could then be followed by the developer to help visualise the relationships between the various screens and the flow of data throughout the software. The following is an example of the client case notes screen:

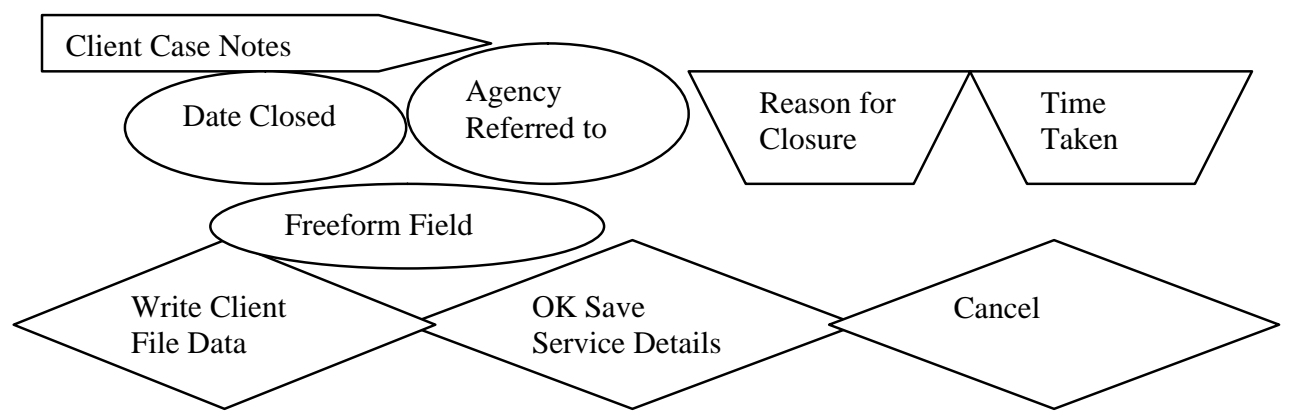

(Appendix v)

The rest of the spec contained a descriptive breakdown of every single aspect of the database based on the flowchart. For instance, the following is an example, again using the client case notes screen, of the descriptive text:

\subsubsection{Client Case Notes}

The Client Case Notes tab is a freeform field using the full text limit with the following fields Date Closed date field

Agency Referred To freeform field with 75 character limit Reason for Closure dropdown with options; Client Needs Met, Client Referred On, Client Withdrew, Budget Service Withdrew, Client Needs Not Met, Other: Please Specify It has the usual save/cancel buttons as well as;

It also has a button Write Client File Data, which saves the data to the harddrive and also writes the file to the data dump.

NB a data field must be completed in each of the Client Details tabs before the Write Client File Data will work, a warning screen could be displayed if incomplete

(Appendix v)

The final project specification came to 17 pages and took the project team over two weeks to compile. This version was still only considered a draft and a further eight specification updates were written and delivered to the developer as work progressed.

The project team and the developer worked very closely over the following months communicating by phone and email as well as holding a number of face-to-face meetings when further brainstorming and 'conceptualising' sessions were required. Some of the requirements of the database were very specific and a considerable amount of time was needed to fine-tune and debug some aspects of the database. 
The finalised first version was ready for deployment by the end of January. This version had been thoroughly tested by both the developer and the project team, although there was a general consensus that a second version would be required. This first version could be likened to a 'beta version' of the software. That is, it worked as far as the project team could tell but needed to be used in real time with real sets of data to show up further faults.

\section{Service Contracts}

The service contracts were designed at the same time as the development work was being carried out. The contracts consisted of two documents. The first document included all of the contractual clauses necessary under NZFFBS service agreement guidelines and included detail (which cannot be reproduced due to commercial sensitivity) under the following headings:

- Project description

- Project objectives

- Service's responsibilities

- Federation's responsibilities

- Termination; and

- Payment and payment scale rates

The second document entitled Client Voices database Administration Tasks (Appendix vi) constituted the service element of the service agreement and included all necessary tasks expected of the six services making up the project team.

The contracts were posted out to each of the services a month prior to the training sessions to ensure they could be considered at a management committee meeting by each service. The contracts were then gone over, clause by clause, during the training sessions to ensure that each service had a good understanding of what was expected of them.

\section{Training}

As mentioned above the original workshop-based training format was able to be conducted in a more informal one-to-one type session. The training was conducted with at least two staff members of each service (a data administrator and usually the service 
coordinator). The training sessions began by going over the 'big picture' of the project to help the services think about how they would fit in to the overall process. This was found to be very beneficial and got the sessions off to a good start.

The programme was then installed to show the service staff how this worked. The entire database was then covered, from setting up the initial control file right through to the reporting and data processing functions, using the CVS Administrator's Manual.

A mock client form was used to allow the database administrators to actually complete a 'dummy-client' record in front of the trainer. This was actually a much more productive form of training than the workshops would have been. This one-to-one process allowed the database administrator to work their way through the various screens in their own time according to their own abilities (which varied greatly). The trainer took a hands-off approach encouraging the administrators to work directly from their Manual and only intervened if the administrator got really stuck.

The training sessions then ended by going over the contract, in particular the Service Agreements, with the Coordinator to ensure they understood what was expected of them in terms of project management and deliverables.

The first training session was held at the Lower Hutt CAB Budget Service. This service had a very competent database user and was used as a testing session to ensure the training was effective. The session went very well and was completed in less than four hours. The five sessions that followed on from this went equally as smoothly. A real measure of the effectiveness of the training was the small number of interactions between the services and the NZFFBS project team that related to database user-issues.

\section{Database Testing}

The database testing phase was coordinated in conjunction with the project monitoring phase. The post-development testing was done in real time in the services and issues were documented in the monitoring reports and later used to create the final version of the database.

Although the database was thoroughly tested in the development phase there were certain process and user-issues that simply could not have been identified until the 
product was in constant use. The services were very open to this concept and provided a wealth of feedback that contributed to a very robust final version.

As well as the process issues mentioned there were a number of issues with the database that were missed during testing. These issues were actually historical and unwittingly built into the database by using the previous NZFFBS's database engine. Considering the consultation that took place this was a communication problem that the project team could have managed better.

Unfortunately, there were also a few structural issues discovered during the testing phase that meant the development of the final version would take considerably longer than what had been planned for. The reporting function was also overhauled during this period as a number of unidentified issues presented themselves that rendered the reporting ineffective.

The issues identified were documented in the project specification updates and are discussed further in the following section. The testing phase, as time-consuming as it turned out to be, was invaluable to the overall outcome of the project.

\section{Project Monitoring}

The project moved into a weekly monitoring phase once the training and initial installation were completed. Email and telephone communication was used extensively over the first two months as teething issues were smoothed out and as helpdesk capacity was required by the database administrators. The time demands in this initial 'bedding in' stage were much greater than originally anticipated, although this was less to do with the capability of the service staff and much more to do with issues with the database.

Although the close contact of the weekly monitoring process placed larger time demands on the project than what was planned for, it enabled the team to analyse the whole process of data collection, from first client contact through to data capture and distribution, in close detail. It was through this analysis that a number of significant changes were made to the forms during the third month of the project including:

- A number of income items were added to the budget worksheet

- A field was added back to the debt schedule at the request of some advisers; and 
- Two demographic questions were dropped from the initial intake form as they were considered too judgemental to ask.

The form changes were included in the three-monthly review where they were presented to, and accepted by, the NZFFBS's Regional and District Representatives. The weekly monitoring reports were also compiled into that review. Immediately following the review the new project specification was worked on and this was delivered to the database developer toward the end of May.

It was at this point that the developer injured himself severely enough to impede his progress on the release of the second version of the database. This was something that, unfortunately, the project team had not included in its risk management plan and had no contingency plan to go forward on.

A number of options were considered at this point to move forward with the development of the database including:

- Outsourcing the programming

- Employing a 'runner' to help the developer; and

- Re-contracting to another developer

Unfortunately, there were too many negatives associated with all of these options and the project team finally made the decision to wait until the developer could begin writing again, which created a major date slippage.

A full two months went by before development work would begin again. The project team used this time to gather more feedback on the database and a number of spec updates were submitted over this time.

\section{Rollout}

The final version of CVS v2.0 was released at the start of August just in time to be installed and to process a full six month dataset from each of the services. A number of delivery methods were trialled during the installation of the new version including disk, email and the internet. It was found during this process that a simple zip file downloaded through a link on the internet located on a purpose-created page on the NZFFBS website was by far the easiest delivery method. The zip file included an executable file and a simple set of instructions on how to install the new version. The 
final task in the rollout phase was the processing and delivery of the six month datasets from all six services. This was completed within a week of installing the updated databases.

\section{Review}

The following project reviews and reports were compiled and delivered to the National Board:

May: Three month review

September: Six month review

October: Eighteen month report

This chapter has discussed in some detail both the methodology and the fieldwork of the Client Voices Pilot project. This project was a considerable undertaking and implemented by a project team that would certainly not consider themselves to be experts in the field of KM. The benefit of this inexperience is that the mistakes inevitably made along the way have been considered learning experiences and documented as such. This documentation will simply add to the creation of knowledge within the NZFFBS and, if managed correctly, will contribute to its growth. The next chapter takes the information documented from the Client Voices project, analyses it and offers a number of recommendations for future KM projects in the community and development sectors. 


\title{
Chapter 6 - Critical Analysis and Recommendations
}

\author{
Jennex and Croasdell in their inaugural editorial... argued that KM \\ has all the features of a discipline and a potential to grow as a distinct \\ discipline. They base their argument on a thorough analysis of the \\ state of the academic research and its relevance to the KM practice. \\ However, the problem with KM... is an abundance of so called \\ organisational case studies. Such studies present success stories that \\ often lack a critical analysis of underpinning assumptions that is \\ needed to generalise what has been learnt to other situations. \\ (Burstein \& Linger, 2006, pg. 2)
}

The final chapter in this thesis is a critical analysis of the Client Voices KM project that includes a number of recommendations for other researchers and practitioners to consider. In the above quote Burstein and Linger express their concern that the current volume of literature relating to KM is not critical enough to be considered academic. It is certainly not the intention of this thesis to be lumped into the 'organisational case study' group of research. It is hoped that the following four sections are critically reflective enough to both be considered 'academic' and also to be of practical use to development practitioners.

The four major issues themes Connectivity, Collaboration, Content and Capacity are once again used in the critical analysis of the Client Voices project and make up the four sections in this chapter. Each section includes a range of issues that were managed both successfully and unsuccessfully while working on the project. At the end of each section is a recommendations section that uses the experience gained on the Client Voices project to offer a number of practical ideas for KM projects in the NGO sector. In all there are 13 separate recommendations that development practitioners will find useful to consider during the design phase of their own KM projects.

\section{Connectivity}

Connectivity was a big issue for the Client Voices project team, although when compared with KM projects in developing countries, was relatively easily managed. There were some hardware and software elements that needed to be developed but the underlying infrastructure made this a fairly straightforward process. 
In the original analysis of the capacity of the whole organisation it was found that some of the budget services did not have computers that would run the new database as it was designed to run on Windows XP; others had no computers whatsoever. Most had email access but often this was through a home computer due to the actual budget service having no internet access. Fortunately, the NZFFBS was able to handpick organisations that had some resources available and, more importantly, human resources who understood how to use them. Although it was acknowledged that this could potentially skew the final results, it was felt that in the beginning stages of the project at least ensuring data integrity was more important

The project team found that most services understood the need for an internet connection. This was especially evident during the member consultation phase of the project where discussion occurred around the wealth of information and resources that are now available to budget services online. Also, there did not appear to be any adverse reaction to the project team pushing the idea of running broadband internet connections only. Most services were actually interested in learning more about broadband internet and some were genuinely surprised that the cost was not significantly greater than that of a dial-up connection.

Connectivity is a major expense item because of the infrastructure that is needed. In Aotearoa-New Zealand the cost is roughly $\$ 2000$ per workstation setup and roughly $\$ 500$ per year per broadband connection. In our original project where we sought to connect 26 of our services this would have created a one-off budget expense item of $\$ 52,000$ and an annual expense item of $\$ 13,000$. Of course there are cheaper options that could be explored than this but there is always a trade-off wherein reductions in the quality of the infrastructure will reduce the overall effectiveness of the KM system.

Connection, itself, is much less of an issue in Aotearoa-New Zealand than many other parts of the world. The historic telecommunications infrastructure ensures that connection is available in most parts of the country. In our original capacity analysis only one of our services was beyond 'the last mile'. Therefore, we did not consider this to be an issue for the Client Voices project.

The Client Voices project team were also successful in negotiating an in-kind donation from a corporate sponsor who offered free 12-month broadband connection packages to 
each of the services in the project team. This further reduced the risk in connecting the services together.

\section{Recommendations}

The first recommendation for connectivity in a KM system in the NGO sector is to spend as much as the project budget will allow. The effectiveness and efficiency of the KM system will ultimately be determined by the quality of the elements that make up that system. Further, as a KM project's success is reliant on the best possible information being sourced and channelled through the system then data quality and integrity are integral features of the project and should be very high up on the risk management schedule. Again, the elements that make up the system will impact on both the quality and the integrity of the final data.

The second recommendation is to look very closely at the evolving possibilities that the internet now offers during the project design phase. In the Client Voices example the project team decided on a system that was connected by email alone. This design meant that the databases used to collect the information were 'offline'. In retrospect, an online database (such as a custom-made, content management system) would have solved many of the data collection and distribution issues that arose as well as offering further opportunities to connect by utilising web 2.0 tools (such as user-groups, blogs, video hosting and other interactive features).

Also, it is very important to remember that the connectivity does not stop once the physical infrastructure is connected up. It is the people involved who are the most important elements in any KM system and they need to feel connected too or the project will quickly move from being one of knowledge management into simply information management; this is something that is to be avoided at all cost.

\section{Collaboration}

As mentioned above, $\mathrm{KM}$ projects are about people, which is why collaboration will be a major aspect of any KM project. The knowledge that a KM system seeks to manage is found inside of people who are, therefore, the single most important element of the system. Also, depending on the size of the project, a number of different groups of people with competing priorities and agendas may make up the project team, which adds to the importance of carefully managing collaboration. 
In the Client Voices project, for example, the project managers came from the NZFFBS, a number of staff from six geographically dispersed community organisations also made up the project team, representatives from government departments and private firms met with the project managers periodically and required project updates and each member of the NZFFBS National Board and all 149 member services were stakeholders in the project. Fortunately for the Client Voices project team this was a great group of people to work with and enthusiasm and encouragement were offered at every turn.

One of the more obvious collaboration issues that arose was the distance of the project team. With seven organisations dispersed from Whangarei to Dunedin there was a definite fracture in communication and, in particular, response time and turn around time of project tasks. Going forward, technology could be the answer to this problem. Technology such as Skype, video-conferencing, internet video, and various web 2.0 tools such as interactive user-groups could be put to good use creating virtual meeting places for the project team. Successfully implementing these tools requires time, knowledge and money but the extra resource would be justified by the buy-in created through an increased level of group cohesion.

Also, the design of the database was intended to replicate the budget services' processes to help to localise the context of the system. This was a key project outcome that was not totally achieved and ownership of the system at the grass-roots level is still an issue. Some form of database customising would be really useful to allow each service to 'brand' their own databases. Extra training in the service-specific features would also go a long way towards helping the services 'own' their part of the overall KM system.

Finally, the project team were well aware that they needed to consider issues around trust building, opinion valuing and participatory methodologies. A substantial amount of project time was utilised breaking the project concept down and discussing it in as many forums to as many stakeholders as possible. A full-day participatory workshop was also held to ensure that the opinions of stakeholders and end-users were heard and ultimately built into the final system.

\section{Recommendations}

The KM project team needs to be able to communicate well with everyone involved in the KM system. KM projects in the community sector may involve very diverse groups 
of people so it is imperative that the project team can clearly communicate their ideas in a number of different ways. This is a key skill that will ultimately decide the outcome of the project. Communicating the KM system as a concept to funders and stakeholders will be key in securing start-up funding. Taking the concept and turning it into a conceptual design to communicate to the system developers will be key to building the system the team envisions. Finally, and most importantly, communicating the system itself to the people who will use it will be key in determining whether or not the system manages actual knowledge or just data. Afterall, the flashiest database with all the bells and whistles will fail to extract any useful knowledge from people that do not understand and, therefore, do not become involved in the KM system.

Secondly, and this too is especially true in the community or development sectors, the project team must recognise upfront that the people they will work with will not necessarily be computer savvy or even computer literate. In order to build good social cohesion to create an environment where knowledge will flow freely a considerable amount of time should be put into developing a process to create good understanding of the system by all involved. This is where pictures, graphs and diagrams will come in handy. A KM system is often a very complex concept to discuss and showing how the elements interact visually will help to break down barriers.

Finally, it will make the project team's job much easier if 'technology champions' are identified and tapped into at the beginning of the project. These people will be more technology literate than the other participants and should be easily recognised by their enthusiasm for the project. Getting these people onboard and involved will help to breakdown barriers as they will help the project team create an environment of trust. Once communication barriers are broken down and trust has been built up the knowledge will begin to flow freely through the KM system and success should follow.

\section{Content}

When it comes to content there are a number of potentially contentious issues that a KM project team needs to navigate. These range from being sensitive to the needs of the project group right through to ensuring the country's privacy and consumer laws are abided by. Whether it is the raw knowledge being extracted or the value-added and repackaged knowledge being disseminated, the project team needs to carefully consider any content ownership issues in the design of the KM project. 
The content in the Client Voices KM system is both client knowledge and budget adviser knowledge. Due to the information extracted during the budget advice process both of these knowledge strands are essentially extracted at the same time. The Client Voices project team spent considerable time consulting with the NZFFBS membership in a number of different formats to ensure the network was comfortable with the NZFFBS extracting budget adviser knowledge. One of the main reasons for the members accepting this project was that the knowledge would be used first and foremost for the benefit of budget services. The second reason for acceptance was that the Client Voices project agreements specifically spelled out that all intellectual property that belonged to each service remained theirs and that the NZFFBS only had rights of use to it.

Extracting the client content was a relatively straightforward process as NZFFBS clients sign an agreement that allows the budget service to collect information on them. The relevant privacy laws had also previously been considered in detail and, as there was no change to the actual budget advice process, did not need to be considered further.

One of the main goals of the Client Voices pilot project was to develop a simple and cost-effective system that was easy to use. This meant that there would be a trade-off somewhere and that trade-off was in the security of the content. A simple email-based system has serious data-security issues and this would need to change going forward. Some level of data encryption is really required to protect the content in the event that it is stolen or somehow leaked; this would also help to prevent a malicious act of data manipulation, which is also a risk. A further security feature could be to use a protected file transfer protocol (FTP) server to channel the encrypted data through. This would also substantially speed up the process and is really no more difficult to use than email.

The project team also needs to look far more critically at the dissemination of the knowledge it is collecting. The content dissemination process, aside from that contained in reports and project updates, is actually beyond the scope of the pilot project. The purpose of the pilot project was simply to prove that the system could work. Although it is accepted that the NZFFBS will use the knowledge gained from this system to become more competitive and to find new avenues of funding, these goals need to be balanced with the needs of the public. The NZFFBS website could be used to disseminate some content to the public for free and a range of statistical and evidenced-based data could 
be made freely available to some government departments and education institutions. Disseminating some knowledge free of charge to the public would also be in keeping with the NZFFBS's ethos of providing free education to the community.

\section{Recommendations}

Content security is a trade-off issue. The more secure the data becomes often the more technical it becomes to use. Fairly simple concepts, like using an FTP server to send data, create immediate training issues; even though the process is similar to sending an email there is a demystification hurdle as well as a training process required. At any rate, all facets of content security need to be considered thoroughly during the project design phase and be placed very high up on the risk management plan as getting this wrong could be extremely disastrous for the project team.

Do not be afraid to ring fence the output from the KM system to use toward your own organisation's ends. If the overall outcome of the project is for the greater good then the potential for increasing competitive edge is simply a bonus outcome for the NGO. A good level of sensitivity, however, is required to ensure that project participants are not being used. Also the project team should spend time considering all of the different ways the community can benefit from the knowledge being collated. That said, if the system can increase competitiveness, grow revenues and open up new funding streams then the NGO should definitely consider this in its strategic planning.

Lastly, consider getting creative in the dissemination phase of the project. All the hard work put into creating an effective KM system will be wasted unless the knowledge can be put to good use. This is definitely the place where the NGO should step outside the box and pop on its creative thinking cap. Value-added and smartly packaged new content can open up new areas of sponsorship and funding, new potential groups of volunteers, supporters and members and new project and programme areas that were previously regarded as too difficult or not even considered at all.

\section{Capacity}

The issues that arise in terms of capacity tend to fall into the two main areas of physical resources and people resources. Capacity issues were perhaps the most difficult of the four themes to manage for the Client Voices project team. Arguably the two most important elements of the Client Voices KM system were the database and the database 
administrators. As both of these elements were outsourced they were only indirectly managed by the project team and both created a number of ongoing issues.

Fortunately, the capacity of the budget services that were involved in the pilot project was more than adequate. In terms of hardware there were only minor issues that needed resolving as explained in the section on connectivity. In terms of people resource the project team was very lucky to have Service Coordinators that were used to working on large collaborative projects and database administrators that had some level of database experience.

That said, the administrators were certainly not proficient in either database use or general computer use and a significant amount of time was taken up by the project team working in its 'helpdesk' capacity. The helpdesk work administered by the project team was far more than originally anticipated and future rollout of the system would need to take this into account. The training programme would also need to be expanded if the KM system was rolled out to increase personnel capacity.

In terms of physical resource the database itself caused many unforeseen problems. Database creation tends to be fraught with difficulty under the best of circumstances, although there were areas that could have been better planned for in the project. The majority of the database testing was undertaken by just one staff member and in hindsight this was simply unrealistic and many programme bugs were missed before the initial rollout as a consequence. Unnecessary time was lost because of this. The project budget dictated this capacity constraint but the upside to this was the decision to do a second round of testing in real time as some database issues could not have been foreseen until it was being used in a real-life situation; in effect the project team made good use of existing people capacity.

The database developer was seriously injured at a crucial stage in the project and this forced an unanticipated timeline slip. Again, budget constraint was actually the underlying reason for this lack of capacity although the project team should have originally assessed this as a risk and had some risk mitigation plan for it.

Finally, it must be noted that by far the largest capacity issue was the lack of funds to roll out the originally scoped project. Success in raising further funds will substantially 
increase both the physical and people capacity of this project and will allow the project team to progress to a full rollout of the system. Whether or not this eventuates remains to be seen.

\section{Recommendations}

The first recommendation for mitigating capacity issues is to be very careful to address every potential capacity constraint in both the project design and the project risk mitigation plan. It is important to be honest about the capacity that is available right at the outset. If this is planned for properly then the project team should know exactly what their capacity constraints are and, more importantly, in which areas capacity can be increased either through personnel development or through resource allocation.

Capacity issues are often glaringly obvious but they can also be somewhat discreet and difficult to detect. It is much more difficult to mitigate capacity issues mid-way through a project, especially one that is working to a tight budget, than at the beginning. It is a far better strategy to increase the capacity in dubious areas at the outset as over-capacity is much easier to manage than under-capacity.

Another important point that is especially relevant for KM projects is to look very critically at the people capacity required by the project. It is all too easy to get caught up in the technology side of the project and focus too much energy in that direction. It is also very easy to mistake people's genuine enthusiasm for ability. In-depth training in the system and ongoing development for all personnel may seem excessive but a knowledgeable group of people is much more efficient to work with. Buy-in will also be a natural outcome of any learning process.

Lastly, some things are just simply beyond the control of the project team. When funding does not eventuate or people are unable to deliver due to random events it can be very frustrating. Still, it is far more productive to immediately begin looking at new ways around unforeseen problems than it is to bemoan any lack of foresight on the part of the project planners. Quality planning and risk management are extremely important aspects of any project and there is little excuse for not getting that right. That said, if mistakes are learnt from then they are probably worth making in the first place; afterall some of the most magnificent advances in human history have come about through mistakes. 


\title{
Chapter 7 - Conclusion
}

\begin{abstract}
Accepting a narrow monetarist perspective of globalisation - often referred to as 'globalisation from above' - will not allow NGOs to pursue their distinctive mission, and it might ultimately alienate them from their roots and purpose. The opportunities must lie in developing a broader understanding of global realities, but one that is critically grounded in what these realities mean for the global majority, and one that is committed to working for a global system which is based on equal rights for all - what some activists refer to as 'globalisation from below'. (Eade \& Ligteringen, 2001, pg. 13)
\end{abstract}

This thesis began by suggesting that knowledge was a resource. Although knowledge is not exactly power as Sir Frances Bacon once said, it does have the potential to wield great power to those who learn to use it wisely. In the case of NGOs this power can be used to do extraordinary things for humankind. Modern NGOs have resources at their disposal comparable to the private sector yet they are in the more enviable position of being able to use those resources to do good things with the expectation of receiving nothing in return. Still, NGOs cannot take their positions for granted as recently discovered by the New Zealand Plunket Society and Mature Employment Support Services in Aotearoa-New Zealand. Like the private sector, there is intense competition for resources in the NGO sector today and smarter organisations are ready to snap these resources up even if means competing directly with fellow NGOs.

Knowledge management is a field that offers NGOs the potential to become smart organisations that can compete, not just with other NGOs, but with the private and public sectors as well to ensure they are competitive enough to stay ahead of the game and to survive for at least the foreseeable future. Knowledge management enables NGOs to extract, from resources that already exist in the organisation, long-lasting value that can be leveraged to give the NGO a real, competitive edge. As Kannappanavar et al. (2007) assert, by systematically managing and leveraging the stores of knowledge in an organisation, NGOs can transform information and intellectual assets into enduring value.

The purpose of this thesis was to present the Client Voices pilot project as an example of the type of knowledge management system that NGOs can use to leverage 
competitive advantage for their long term success. A substantial part of the thesis was dedicated to providing a detailed analysis of this project so that community and development sector practitioners could examine a real-life example of the sort of system that can be created to manage the 'stores of knowledge' within their own organisations. Right throughout the thesis real examples have been used to show the practical applications that KM theory has.

The theory behind KM (and that of competitive advantage) is important to understand as a basis for an effective KM system. Wherever the practical applications of KM were highlighted, the theory behind these concepts was also discussed. NGOs need to understand the purpose and potential of KM before delving into developing their own KM system. For, without a defined purpose and a good understanding of its potential, a $\mathrm{KM}$ system can quickly turn into simply an information system. For this reason, the thesis discussed the theoretical implications of both KM and competitive advantage as a first step for NGOs to consider in their path toward managing knowledge for growth.

Finally, 13 recommendations were offered under the four key KM project issues for consideration. The four key issues themes were used because most KM issues will fall under one or more of these themes. This, in itself, is a key idea as using these themes in the initial planning stages of a KM project will substantially reduce the issues that could otherwise arise. The recommendations offered are practical ideas, drawn from experience, and intended for practitioners working with NGOs but are also based on the theory behind the KM concept and are just as relevant for consideration by KM and development theorists alike.

\section{Looking Forward}

Knowledge management in relation to competitive advantage in the NGO sector is a fledgling field of research that demands more attention from academics and practitioners alike. This is a fascinating area of study with practical application that can improve the competitiveness of NGOs to the point where they are able to make strategic decisions based on information rather than assumptions. These decisions could well mark the success, or otherwise, of the organisation over the long term. For this reason a substantial increase in the volume of literature in this field is required. 
The Client Voices project was severely restricted in its scope due to a lack of funding. The point of the project, however, was to prove that the KM system was flexible, replicable and sustainable. Only time will tell if this has proved to be the case. So far the project is still up and running and work progresses on accessing new funding streams to roll the project out throughout the entire organisation. The future is unknown... yet exciting!

Interestingly, the pilot project has been a valuable enough experience to bring out many of the underlying assumptions of KM projects and KM systems generally; that is, the theory behind knowledge management. The NZFFBS is proactively learning about and testing those assumptions and new insights continue to be gained all the time. Any mistakes that have been made so far have been considered learning experiences and the organisation continues to grow through the process of trying to understand itself better. This really is cutting edge research for the community and development sectors and this is reflected by the fact that even the United Nations has only just begun moving down the path toward managing knowledge for growth.

UN Adopted Resolution 57/295 from the fifty-seventh session of the General Assembly contains a request for the Secretary-General, "to develop a comprehensive information and communication technologies strategy for the United Nations system" (2007, [online]). In his report to the fifty-ninth session of the Assembly in response to Resolution 57/295, then Secretary General, Kofi Annan stressed that the aim of knowledge management in the UN is to leverage the wealth of information from within the organisation to maximise its results:

\footnotetext{
Knowledge management should not be seen purely as a technologydriven process but rather as a policy imperative, facilitated by technology to better manage and put to use the system's intellectual and business assets. KM decisions should be based on who (people), what (knowledge) and why (business objectives); leaving the how (technology) to be derived from the first three dimensions. In this perspective, the basic aim is to leverage [the] wealth of information currently available within the United Nations system to maximize impact and results. (2007 [online])
}

Community and development sector organisations that have not even begun to consider $\mathrm{KM}$ as a source of growth can take some comfort in the fact that an organisation such as the UN has only recently begun to come to terms with this strategy. That said it is 
imperative that those organisations do begin to think about KM in this way. In the new knowledge society organisations that choose to bury their heads in the sand and ignore $\mathrm{KM}$ as something that is just too complicated run the risk of stagnating and eventually losing out to competitors. As discussed throughout this thesis this eventuality is just as real for the community and development sectors as it is for private business. The next and final section in this thesis progresses this idea further. It considers the global implications of utilising $\mathrm{KM}$ as a source of competitive advantage in the development sector.

\section{Global Implications}

The knowledge society is the global concept relating to Peter Drucker's (1959) term 'knowledge worker'. Drucker identified that a transformation was taking place from manufacturing-based societies to those based on knowledge. He correctly predicted that workers would use information and knowledge as the basis for growth in the future. This is a key concept for NGOs to come to terms with. All NGOs now exist in the global society whether they realise it or not. It can be difficult for smaller NGO workers at the grass roots level to understand that they are now a part of the global economy.

It can be equally as difficult for grass roots NGO workers to understand how their funding agreement has suddenly been contracted to another, more efficient, organisation. The reality, however, is that this is a case of the contractor making an economically rational decision to use its limited resources in the most efficient way. The impact of the global economy on the NGO sector has required NGOs to recruit at the international level to find quality staff and pay ever-increasing wage rates to retain them. Growth has become a necessity for these NGOs to keep their competitive edge in this global environment and competition has become inevitable.

Retraining NGO staff as 'knowledge workers' in the Drucker sense is the only real answer to competing in the global economy. Interestingly, many NGO workers already are knowledge workers, they just do not realise it yet. Retraining NGO staff to think like knowledge workers, then, may be all that is needed to begin the process of accumulating and managing knowledge for growth. Once staff are thinking like knowledge workers they will begin to see themselves differently. Rather than cogs in a great wheel, these workers will begin to see themselves as integral parts of their organisations. They will discover that the resource that is their own knowledge can be 
woven into the very fabric of their organisations making it almost indistinguishable as to where their thoughts end and their organisation begins. The efficiencies that flow from well managed KM systems will entice these new knowledge workers to pursue both the acquisition and utilisation of knowledge which will lead to organic growth that the workers will really feel a part of.

The next ten years will see enormous change in the development sector. The sector has grown massively albeit haphazardly over the last few decades and is now highly fragmented. The next ten years will see a substantial amount of consolidation in the sector through mergers, acquisitions and from share brute competition. There are just too many organisations competing for finite resources for historical growth to continue. The sector has, in fact, already seen this competitive force take place. There are now a number of mega-NGOs competing in the sector, which are continually looking for new income streams to keep growing. The likes of World Vision, Save the Children Foundation, BRAC, Oxfam, etc. are multi-national conglomerates that appear much more like private sector corporations than classic development sector NGOs. These mega-NGOs, the proliferation of small to medium (or SME-NGOs) as well as the multitudes of tiny, grass roots NGOs collectively work in a sector worth more than a $\$ 1$ trillion a year globally and growing. The sector employs over 19 million paid staff let alone the masses of volunteers also involved (Public Services International, 2008). Development sector NGOs must acknowledge the enormous size of their sector and start creating new models of working to compete in it. No matter how small an NGO is or how unique its offering the global economy has arrived on its doorstep. Unless it develops new models of working, such as a growth through KM model as outlined in this thesis, it will find itself ill-prepared to compete in the global development sector.

There is a possible alternative to the inevitability of development sector globalisation. This thesis has discussed the unique properties of knowledge that make it the "ultimate economic renewable'. Knowledge is a unique resource in that no matter how much it is used it is not diminished. In fact, equally unique is the characteristic of knowledge to increase when it is collected together; this growth is compounded and therefore grows exponentially. The development sector has a unique opportunity to utilise this resource for the good of the whole sector; as opposed to the private sector that hoards this resource in order that competitors cannot access it. 
Is there the potential for a model whereby NGOs can leverage knowledge for competitive advantage yet still freely disperse that knowledge to its competitors? The answer to this question comes directly from the ICT sector. The internet has spawned an amazing phenomenon, which is commonly now known as 'open-source'. The concept of open-source is that knowledge can be freely shared while at the same time organisations can exploit that knowledge for growth.

An obvious conclusion that came from the project outlined in this thesis was that there was no 'open-source' fix for the problem it was trying to solve. Certainly, there was a lot of information on various models of KM systems and many articles on different KM systems currently in use by NGOs but there was no source of knowledge that prevented the wheel from being recreated. This is an inefficient and ultimately wasted use of resources. If the Client Voices project team does not disperse its findings (which it plans on doing with this thesis being part of that dissemination process) then that knowledge is lost and another NGO must recreate yet another wheel to solve the same problem.

Peter Drucker also predicted this problem and, in his later years, was integral in teaching the NGO sector how to teach itself. The organisation he founded, now known as the Leader to Leader Institute, is actively trying to build up and disseminate stocks of knowledge. This knowledge is freely available to all NGOs and there are many other organisations posting best-practice documents, how-to-do-it manuals and case study analyses. This is knowledge management at its best. This is knowledge that has been turned into a public good; a freely available commodity and one that grows the more it is used. Managed in this way the same unit of knowledge can be leveraged for growth by any number of NGOs indefinitely. This is a new global ideal; one that the successful open-source concept has paved the way for.

A repository and conduit of knowledge freely available to the NGO sector is not a new or novel concept but it is still an unrealised ideal. Fortunately, there are a growing number of organisations working actively to turn this ideal into a reality. Knowledge by itself, of course, will do nothing to help an organisation incapable of managing that knowledge to grow and become more competitive. The fact that the knowledge is out there however, that it is growing all the time and is freely available should be more than enough to encourage the enthusiasm of those NGOs committed to utilising knowledge for growth. It is these NGOs that will lead the development sector into the future. 


\section{Bibliography}

Argote, L. and Ingram, P. (2000). Knowledge transfer: a basis for competitive advantage in firms. Organizational Behavior \& Human Decision Processes, 82(1), 150-169.

Asian Development Bank. (2003). Information and Communication Technology for Development in the Pacific. Philippines: Asian Development Bank.

Ballantyne, P., Labelle, R. and Rudgard, S. (2000). Information and Knowledge Management: Challenges for capacity builders. (Policy Management Brief No. 11). Maastricht: ECDPM.

Brinkley, I. (2006). Defining the Knowledge Economy: Knowledge economy programme report. London, UK: The Work Foundation.

Bebbington, A. \& Thiele, G. (1993). Non-Governmental Organisations and the State in Latin America. London, UK: Routledge.

Birol, F. (2007). Energy Economics: A Place for Energy Poverty in the Agenda? The Energy Journal, 28(3) 1-6.

Boisot, M. (1998) Knowledge assets: securing competitive advantage in the information economy. New York, USA: Oxford University Press.

Boven, K. and Morohashi, J. (2002) Best Practices using Indigenous Knowledge. Paris, France: UNESCO.

Burstein, F. \& Linger, H. (2006). Introduction to the special issue: An Australian perspective on organisational issues in knowledge management, International Journal of Knowledge Management, 2(1), 1-5.

CABI. (2007). Using the Internet to Grow Better Crops in Sri Lanka. Retrieved 04 September 2007 from: http://www.cabi.org/datapage.asp?iDocID=612

Capra, F. (1976). The Tao of Physics: An exploration of the parallels between modern physics and eastern mysticism. London, UK: Fontana.

Carneiro, A. (2000). How does knowledge management influence innovation and competitiveness? Journal of Knowledge Management, 4(2), 87-98.

Carrillo, F. (2002). Notes on knowledge-based management. Journal of Knowledge Management, 6(4), 1-22.

Choo, C. W. (1998) The Knowing Organization: how organizations use information to construct meaning, create knowledge, and make decisions. New York, USA: Oxford University Press.

CELAC (2006). Combining the Power of Knowledge Sharing \& Technologies to Improve Rural Livelihoods. CELAC Annual Report 2006. Retrieved 03 September 2007 from: http://celac.or.ug/index.php?option=com_content\&task=view\&id=20\&Itemid=2 8

CELAC. (2007). About CELAC. Retrieved 03 September 2007, from: $\mathrm{http} / / /$ celac.or.ug/index.php?option=com_content\&task=view\&id=5\&Itemid=6

CityLife Porirua. (2008). Job Service Axed. Retrieved 21 January 2008 from: http://www.poriruacity.com/multimedia/pdf/2008_01_10/12.pdf

Conway, P. (2002). A New Zealand Council of Trade Unions Perspective on the "New Zealand Experiment". GPN Asia/Pacific Regional Meeting: NZCTU.

Consumer's Institute. (2007). New Credit Law Passed. Retrieved 11 August 2007 from: http://www.consumer.org.nz/newsitem.asp?docid=1689\&category=News\&topic $=$ New $\% 20$ credit $\% 201$ aw $\% 20$ passed

Consumer's International. (2007). Asia Pacific Consumer. Retrieved 17 June 2007 from: http://www.consumersinternational.org/shared_asp_files/uploadedfiles/B2341A 29-23EF-4104-A2E5-AC40D0644B99_AP34-part2.pdf 
Cornforth, C. (2002). The role of boards in small voluntary organisations. In C. Cornforth (ed). The Governance of Public and Non-profit Organisations. London, UK: Routledge.

Davenport, T. H., De Long, D. W. and Beers, M. C. (1998). Successful Knowledge Management Projects. Sloan Management Review, Winter Edition, 43-57.

Davenport, T. K. and Prusak, L. (1998). Working Knowledge: How organizations manage what they know. Boston, USA: Harvard Business School Press.

Digital Strategy. (2007). The Community Partnership Fund. Retrieved 13 June 2007 from: http://www.digitalstrategy.govt.nz/Funding/The-Community-PartnershipFund/

Drucker, P. (1959). Landmarks of Tomorrow: A Report on the new 'post-modern' world. New York: Harper.

Eade, D \& Ligteringen, E. (2001). NGOs and the Future: Taking stock, shaping debates, changing practice.

Eade, D. (1997). Capacity-Building: An approach to people-centred development. London, UK: Oxfam.

Ernst, L. (1998). Agriculture and the Environment: Perspectives on sustainable rural development. Washington, USA: World Bank.

Fulmer, R. M., Gibbs P. and Keys. J. B. (1998). The second generation learning organizations: new tools for sustaining competitive advantage. Organizational Dynamics, 27(3), 6-21.

Ganga, P. G. L., Amitav, N. and Rakesh, M. Community content sharing: towards telecentre's lab to land approach. International Journal of Education and Development using Information and Communication Technology, 2(4), 128-136.

Global Grid for Learning (2008). The 4C Initiative - Content, Connectivity, Collaboration and Capacity. Retrieved 18 July 2007 from: http://www.globalgridforlearning.com/needmoredetails/globalgridforlearningorg .htm

la Grange, M. E. (2006). The Relevance of Knowledge Management in the Public Sector: The measure of knowledge management in government. Retrieved 14 August 2007 from: https://ir.sun.ac.za/dspace/bitstream/10019/91/1/LagraME.pdf

Green, G.P., \& Haines, A. (2002). Asset Building and Community Development. London, UK: Sage.

Guzman, M. S. (2007). Using ICTs for knowledge sharing and collaboration: an international experience based on bellanet's work in the south. Knowledge Management for Development Journal, 3(1), 68-78.

Harris, M. (1996). Do We need governing bodies? In D. Billis and M. Harris (eds). Voluntary Agencies: Challenges of organisation and management. London, UK: Macmillan.

Harris, R. W. (2004). Information and Communication Technologies for Poverty Alleviation. UNDP-APDIP: Malaysia.

Heeks, R. (1999). Information and Communication Technologies, Poverty and Development. Development Informatics Working Paper Series. Retrieved 21 August 2007 from:

http://www.sed.manchester.ac.uk/idpm/research/publications/wp/di/documents/d i_wp05.pdf

Hildebrand, C. (1999). Making KM Pay Off. CIO Enterprise Magazine, February, 6466.

Hurley, T. A. and Green, C. W. (2005). Knowledge management and the nonprofit industry: a within and between approach. Journal of Knowledge Management Practice. Retrieved 21 January 2008, from: http://www.tlainc.com/articl79.htm 
Internet World Stats. (2007). Internet World Stats: Usage and population statistics. Retrieved 14 August 2007 from: http://www.internetworldstats.com/top25.htm

Kannappanavar, B., Rajanikanta, S., Vijayakumar, M. Information and Knowledge Management. Retrieved 22 July 2007, from: http://dspace.inflibnet.ac.in/bitstream/1944/540/1/259-272(cal+07).pdf

Karamagi Akiiki, E. (2006). Towards improving farmers' livelihoods through exchange of local agricultural content in rural Uganda. KM4D Journal, 2(1), 68-77.

Kinney, T. (1998). Knowledge management, intellectual capital and adult learning. Adult Learning, 10 (2), pp. 2-5.

Kong, E. (2007). The development of strategic management in the non-profit context: Intellectual capital in social service non-profit organizations. International Journal of Management Reviews. Retrieved 21 January 2008, from: http://www.blackwell-synergy.com/doi/abs/10.1111/j.1468-2370.2007.00224.x

Land, G. (1973). Grow or Die. New York, USA: Random House

Leeming, D. (2007). Challenges for Sustainable Rural Networking in Solomon Islands: The People First Network. 2003 Round Table on Developing Countries Access to Scientific Knowledge. Retrieved 08 September 2007 from: http://www.ejds.org/meeting2003/ictp/papers/Leeming.pdf

LePla, F. J., Davis, S. V. \& Parker, L. M. (2003). Brand Driven. London, UK: Kogan Page.

MarkIntell. (2007). Competitive Intelligence Terminology Glossary. Retrieved 23 July 2007 from: http://www.markintell.com/language-business-intelligence/

Mathison, S. (2004). Digital Dividends for the Poor: ICT for poverty reduction in Asia. Malaysia: Global Knowledge Partnership Secretariat.

MCA. (2004). Identifying Consumers 'At Risk': Benchmark survey of consumer credit behaviour and knowledge. Wellington, NZ: Ministry of Consumer Affairs.

MCA. (2007). Credit Contracts and Consumer Finance Act. Retrieved 11 August 2007 from: http://www.consumeraffairs.govt.nz/businessinfo/cccfa/index.html

MCA. (2007a). Creating Confident Consumers: The role of the Ministry of Consumer Affairs in a dynamic modern economy. Retrieved 29 July 2007 from: http://www.consumeraffairs.govt.nz/aboutus/review/report/report.pdf

Microsoft. (2007). Knowledge Management and Collaboration Training Roadmap. Retrieved 21 August 2007 from: http://www.microsoft.com/technet/archive/exchangeserver55/plan/collabrm.msp $\mathrm{x}$ ? $\mathrm{mfr}=$ true

Narayan, D., Patel, R., Schafft, K., Rademacher, A. and Koch-Schulte, A.. (2000). Voices of the Poor: Can Anyone Hear Us? New York, USA: Oxford University Press

Narayan, D. and Petesch, P. (2002). Voices of the Poor from Many Lands. Washington, DC: The World Bank.

Ndlela, L. T. and du Toit, A. S. A. (2001). Establishing a knowledge management programme for competitive advantage in an enterprise. International Journal of Information Management, 21(2), 151-165.

Nonaka, I. and Takeuchi, H. (1995). The Knowledge Creating Company. New York, USA: Oxford University Press.

NZFFBS. (2004). The National Budgeting Plan. Wellington, NZ: NZFFBS.

NZFFBS. (2005). Memorandum of Understanding. An agreement between the NZFFBS and Ministry of Consumer affairs.

NZFFBS. (2006). Client Voices Project Description 2006. NZFFBS project background document.

NZFFBS. (2006a). Report to the National Board. Project update document, November 2006.

NZFFBS. (2007). Report to the National Board. Project update document, February 2007.

NZFFBS. (2007a). Report to the National Board. Project update document, May 2007. 
NZFFBS. (2007b). NZFFBS Statistical Analysis to 30 June 2007. Wellington, NZ: NZFFBS.

NZFFBS. (2007c). NZFFBS Website. Retrieved on 26 July 2007, from:

http://www.familybudgeting.org.nz

Okpaku, J., (2003). Information and Communications Technologies for African Development. United Nations ICT Task Force.

PFnet. (2007). What is PFnet? Retrieved 08 September 2007 from: http://www.peoplefirst.net.sb/general/PFnet.htm

Public Services International (2008). Retrieved 24 May 2008 from: http://www.worldpsi.org/TemplateEn.cfm?Section=Whats_New\&CONTENTID=11741\&TEMPL ATE=/ContentManagement/ContentDisplay.cfm\#_ftn1

Polanyi, M. (1995). The Tacit Dimension. New York, USA: Double Day.

Porter, M. E. (1985). Competitive Advantage: Creating and sustaining superior performance. New York, USA: The Free Press.

Porter, M. E. (1985a). How information gives you a competitive advantage. Harvard Business Review. 63(4), 149-161.

Porter, M. E. (2001). Strategy and the internet. Harvard Business Review. 79(3), 63-68.

Sargeant, A., \& Jay, E. (2004) Fundraising Management: Analysis, planning and practice. London, UK: Routledge.

Sarvodaya. (2007). Why, Who, What, Where... Sarvodaya? Retrieved 09 September 2007 from:

http://www.sarvodaya.org/users/situ/index.php?option=com_content\&task=view \&id $=56 \&$ Itemid $=61$

Spencer, J. (1998). Who Moved My Cheese? An Amazing Way to Deal with Change in Your Work and in Your Life. New York, USA: Penguin Putnam Inc.

Statistics NZ. (2001). Information Technology Use in New Zealand. Wellington, NZ: Statistics NZ.

Streatfield, D. and Wilson, T. D. (1999). Deconstructing knowledge management. Aslib Proceedings, 51(3), 67-72.

Talyarkhan, S., Grimshaw, D. J. and Lowe, L. (2007). Reaching the Last Mile. Retrieved 11 January 2008 from:

http://www.knowledgesystems.org/e100mty/inputs/General_KBD_inputs/kbd_fi les/001_introductory/carrillo_notes_on_KBD.pdf

TVNZ. (2008). Plunketline Shocked Over Funding Axe. Retrieved 21 January 2008 from: http://tvnz.co.nz/view/page/425826/697239

UN. (2000). Millennium Development Goals. Retrieved on 26 August 2007, from: http://www.un.com.

UN. (2003). Resolution Adopted by the General Assembly. Retrieved 06 February 2008 from: http://seagrass.goatchurch.org.uk/ undemocracy/undata/pdf/A-RES-57295.pdf

UN. (2005). Information and communication technologies for development: Progress in the implementation of General Assembly resolution 57/295. Retrieved 06 February 2008 from: http://www.un.org/esa/documents/draft44ict.pdf

UN. (2005a). The Digital Divide Report: ICT diffusion index. Retrieved 19 September from: http://www.unctad.org/en/docs/iteipc20065_en.pdf

UNESCO. (2007). Discussion of Key Themes. Retrieved 29 August 2007 from: http://www.comnet.mt/UNESCO/Survey1999/English/report/m3diskt.htm

USAID (2007) Africa's Health in 2010. Capacity strengthening of african institutions and networks: A Strategy. Retrieved 03 September 2007, from: http://www.letkidslead.org/ToolsandPublications/upload/CapacityStrengthening _for_GHPN_Jan2007.pdf 
van der Velden, M. (2002). Knowledge facts, knowledge fiction: Notes on the role of ICT in knowledge management for development. Retrieved 19 July 2007 from: http://www.xs4all.nl/ maja/docs/maja/jid2002.pdf

Widmer,C. (1993). Role conflict, role ambiguity, and role overload on boards of directors of nonprofit human service organizations. Nonprofit and Voluntary Sector Quarterly, 22(4), 339-356.

Wilmott, H. (1998). Here Today, Gone Tomorrow? In Knowledge Management: A Real Business Guide. London, UK: Caspian Publishing Ltd.

World Bank (1998). World Development Report. Washington, DC: World Bank.

World Bank. (2000). Rural Access to Information and Communication Technologies: The Challenge for Africa. Kenya: World Bank.

World Bank. (2002). Ayuda Urbana: Creating communities on urban issues. Thematic Group on Services to the Urban Poor, Number 5, 1-4. Retrieved 01 September 2007 from: http://siteresources.worldbank.org/KFDLP/Resources/4611971148594717965/2586681-1149180172217/ayudaurbana.pdf

World Bank. (2007). AyudaUrbana.com: An UCCI/World Bank knowledge sharing initiative for municipal capacity building. Retrieved 01 September 2007 from: http://www.worldbank.org/html/fpd/urban/upgrading/docs/ottawa/ayudaurbanapres.pdf

World Bank. (2007a). KM Stories. Retrieved 01 September 2007 from: http://web.worldbank.org/WBSITE/EXTERNAL/WBI/WBIPROGRAMS/KFD LP/0,,contentMDK:20942073 pagePK:64156158 piPK:64152884 theSitePK:4 $61198,00 . h t m l$

Zúñiga, L. (2007). Medios y materiales para compartir conocimientos. In S. Burch (ed). Compartir Conocimientos para el Desarrollo Rural: Retos, experiencias y métodos. Quito, Ecuador: Agencia Latinoamericana de Información. 


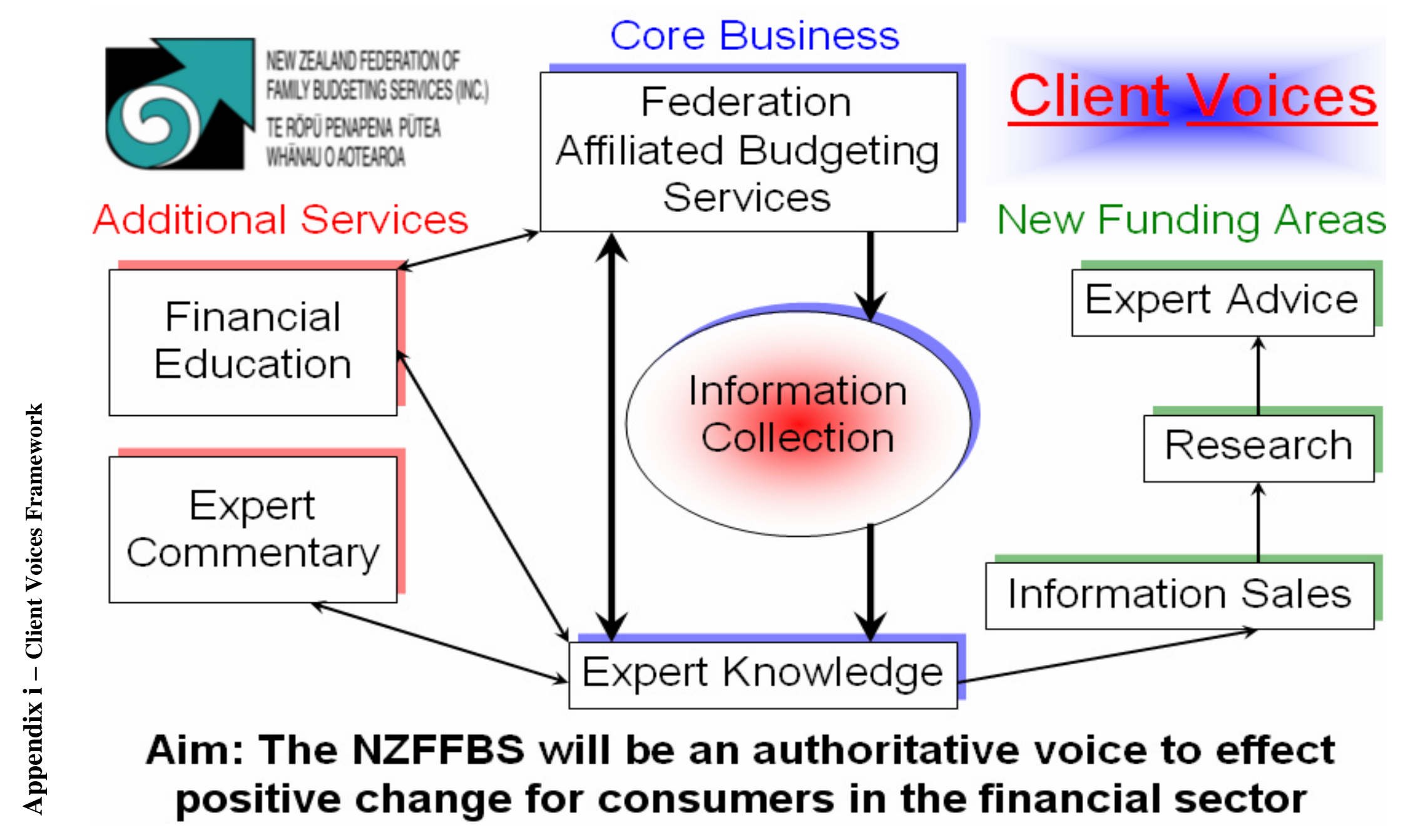




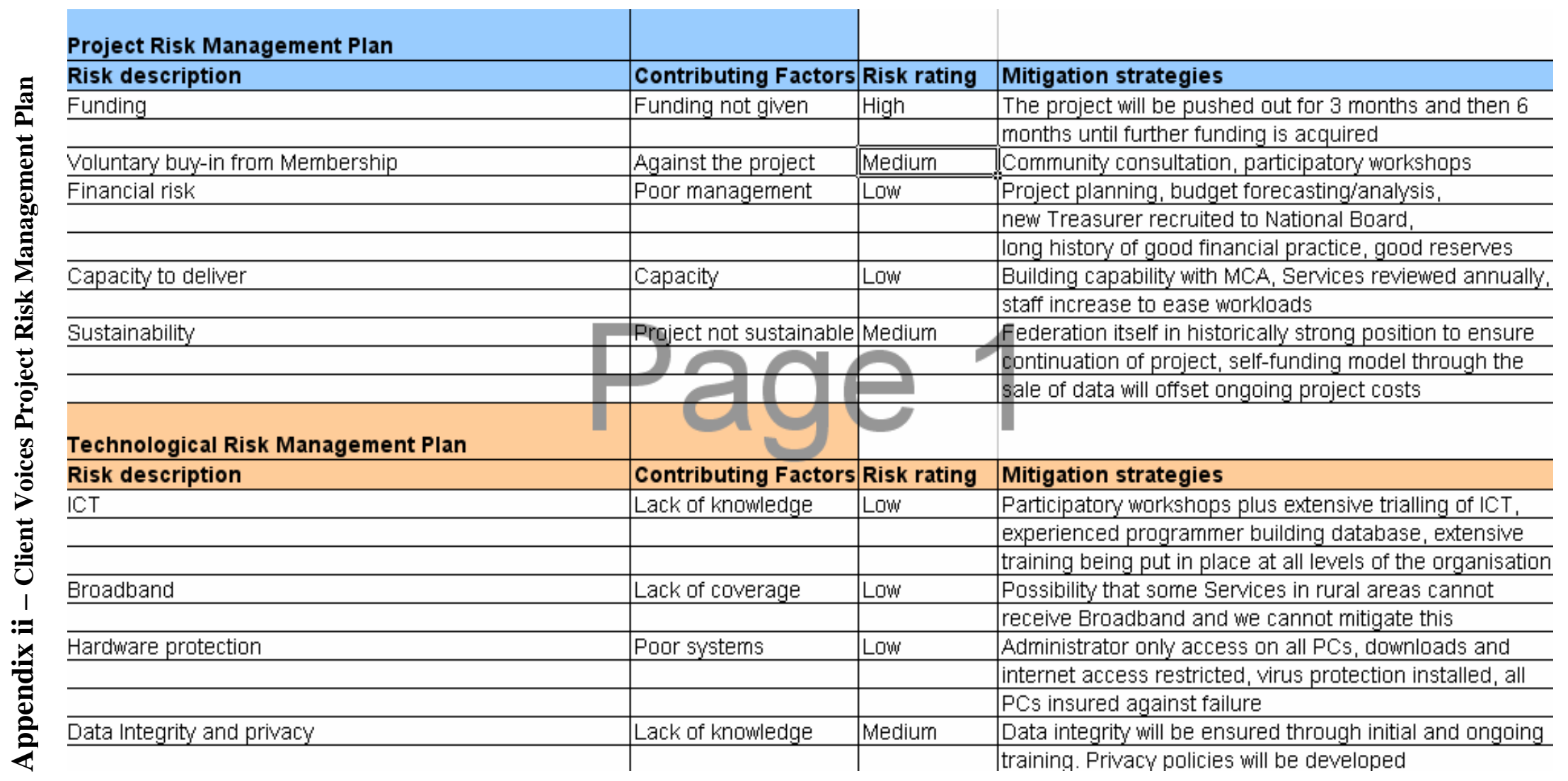


Client Voices Project Proposal - Funding Plan and Budget

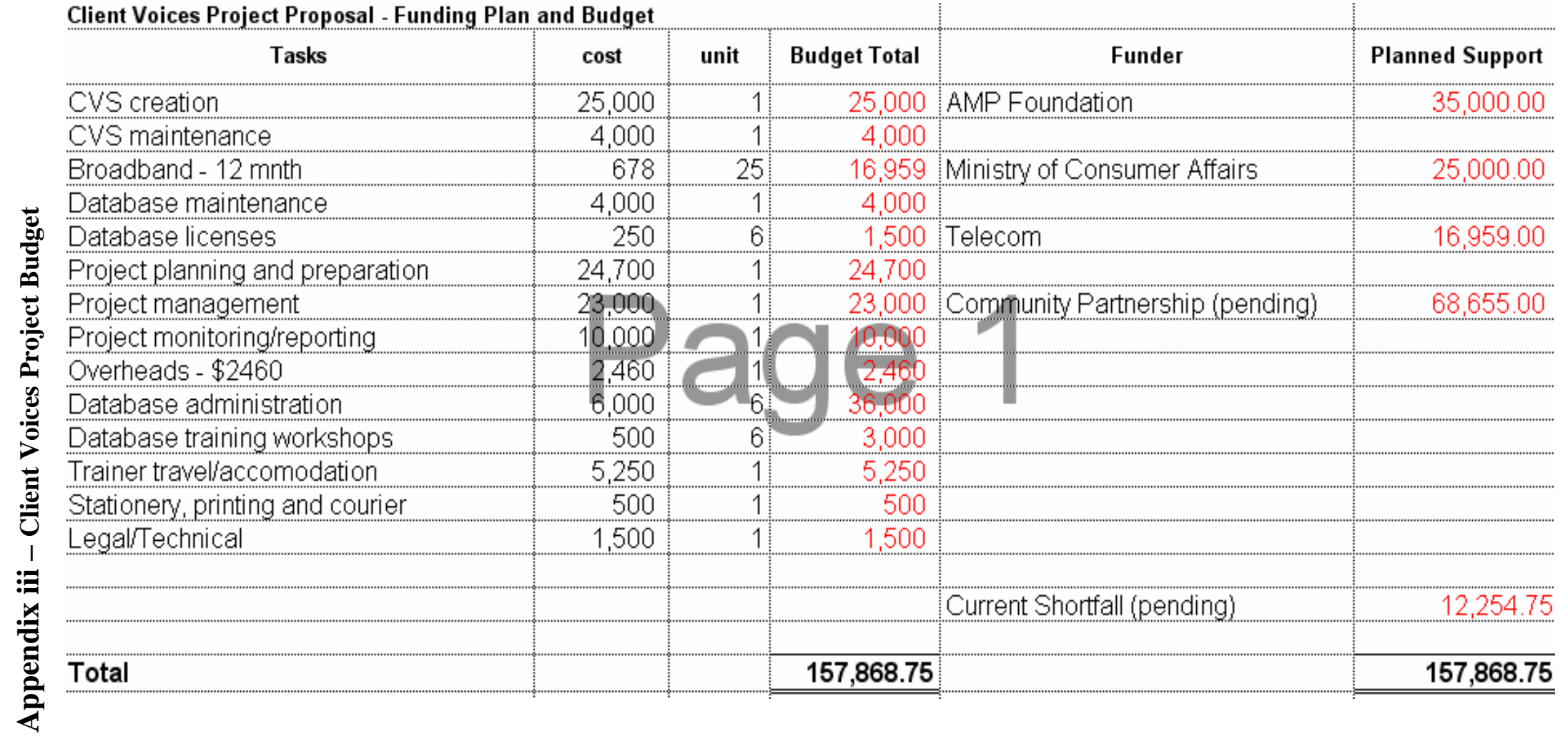




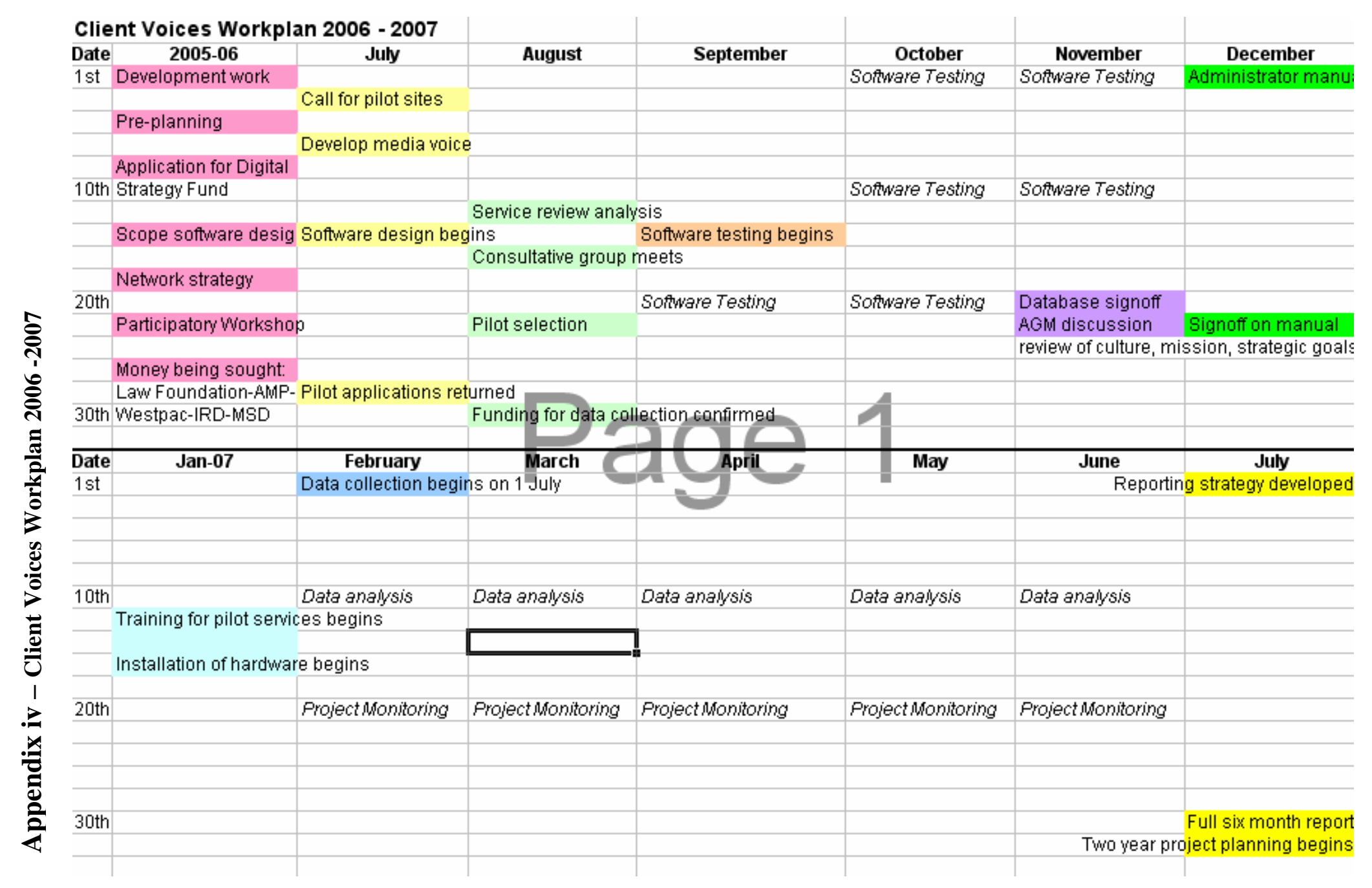


Appendix v - Client Voices Project Specification - Extract

NZFFBS Inc Project Specification Client Voices System (CVS)

Contents

Page

1.0 Project Definitions

1.1 Application Definition

1.2 Application Model

1.3 End-user Definitions

2.0 Application Definitions

3.0 Application Flowchart

3.1

3.2

3.3

1

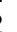

4

4.0 Application Details

4.1

4.1.1 Service Details

4.1.2 Details Continued

4.2

4.1.3 Service Notes

8

8

8

8

8

4.2.1 General

4.2.2 Position 9

4.2.3 Training 10

$\begin{array}{ll}4.3 & 10 \\ 4.2 .4 \text { Staff Notes } & 10\end{array}$

4.3.1 List of Advisers 10

4.3.2 Browse Client Records $\quad 10$

4.3.3 Client Details $\quad 10$

4.3.4 Client Budget Worksheet 13

4.3.5 Client Debt Schedule $\quad 14$

4.3.6 Adviser Worklog $\quad 15$

4.3.7 Client Case Notes $\quad 15$

15

5.0 Client Confidentiality and Data Protection 16

$\begin{array}{ll}\text { 6.0 Extra Credit Contract Screen } & 17\end{array}$

7.0 Data Export/System Tools/Reports 17

Appendices

Client Initial Intake Form

Client Budget Worksheet

Client Debt Schedule

Client Case Notes 


\title{
Appendix v - Client Voices Project Specification - Extract
}

\author{
NZFFBS Inc Project Specification \\ Client Voices System (CVS)
}

1.0 Project Definitions

1.1 Application Definition

The Client Voices System (CVS) is a database with two major functions. Its primary function is to collect information on budget service clients and collate this information into a suitable format able to be sent electronically to the Federation.

Its secondary function is as a management tool that will be used by budget service Coordinators/Managers to manage information relating to budget service staff. Also, a range of reports based on the above information will be accessible for management purposes.

\subsection{Application Model}

The CVS database will be modelled on the existing Client Management System (CMS). There will be some design changes, although these are mostly cosmetic. New features and screens will be added and existing features and screens will be extended and improved.

\subsection{End-user Definitions}

Coordinator/Manager: The manager of a budget service. They require the database to manage staff information, to create reports for their Committees, and to analyse client information.

Budget Adviser: The Budget Adviser will collect information from clients in paper based form and may, or may not, directly use the database but will be effected indirectly by its function.

Database Administrator: The staff member(s) tasked by the budget service to input data into the CVS. The Administrator will have full knowledge of the application including report creation, data extraction, and administrator tasks.

NZFFBS Inc: The Federation has ultimate accountability for the CVS. The Federation will also receive a consistent flow of extracted data from each database. The Federation's analysis of this data will use separate applications from the CVS but it will be directly effected by its functions.

\subsection{Application Definitions}

Toolbar: Top navigation to database screens

Screens: 'Windows' accessed from the toolbar that display data

Display Screens: 'Windows' without fields that display prepopulated data

Tabs: Navigation to specific fields contained in the screen entered

Fields: Areas within tabs allowing the input of data

Dropdowns: 'Menus' offering certain pre-specified data to be entered into a field

Buttons: Areas on screens that can be clicked to action specific features

Reports: Special toolbar option allowing access to pre-defined collections of data

Note: in the following there are no stats reports or system tools tabs included. There will be both in the final application and these will be worked out with the Developer during programme writing 


\section{Appendix v - Client Voices Project Specification - Extract}

\subsection{Application Flowchart}
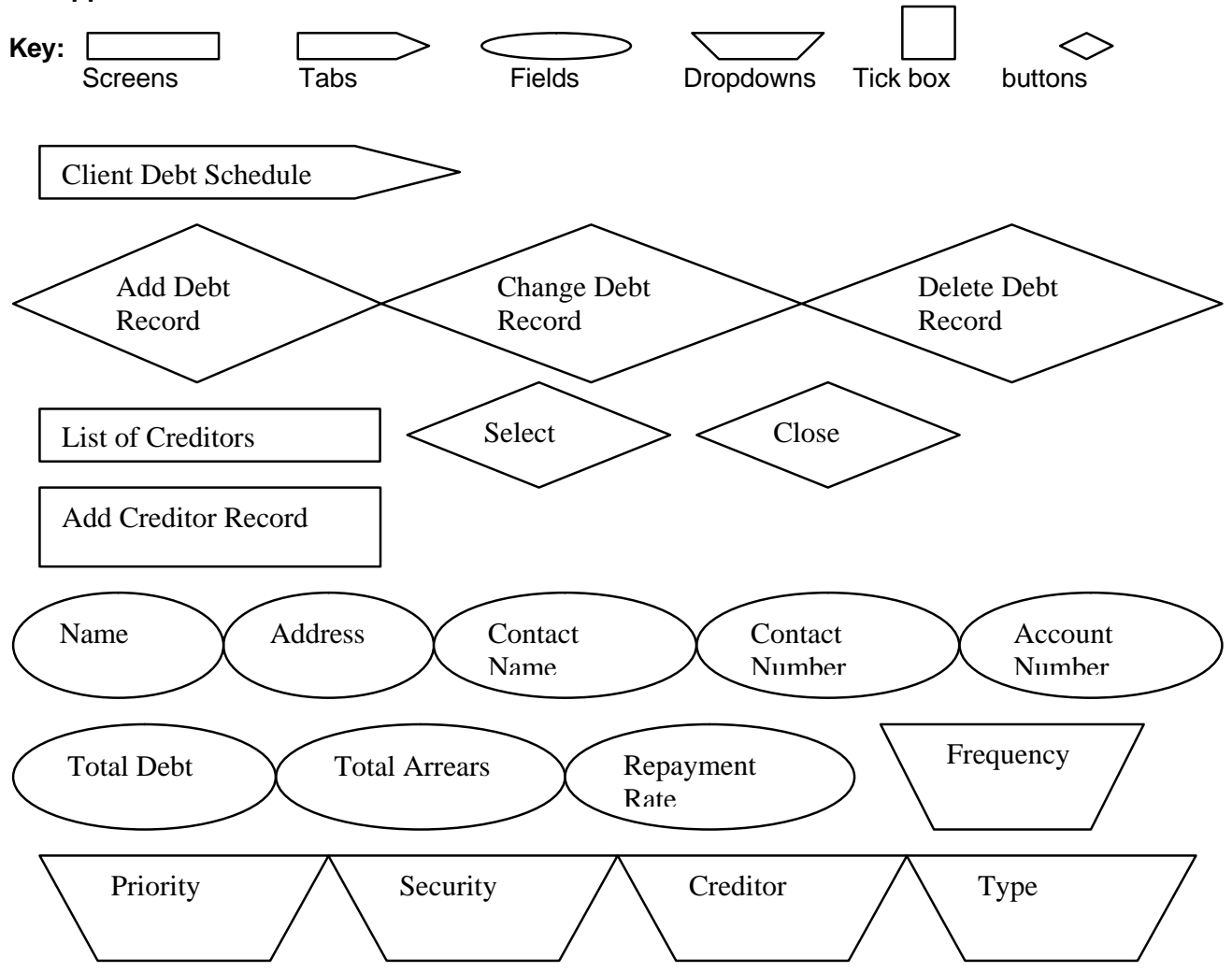

Add to

Budget

Worksheet
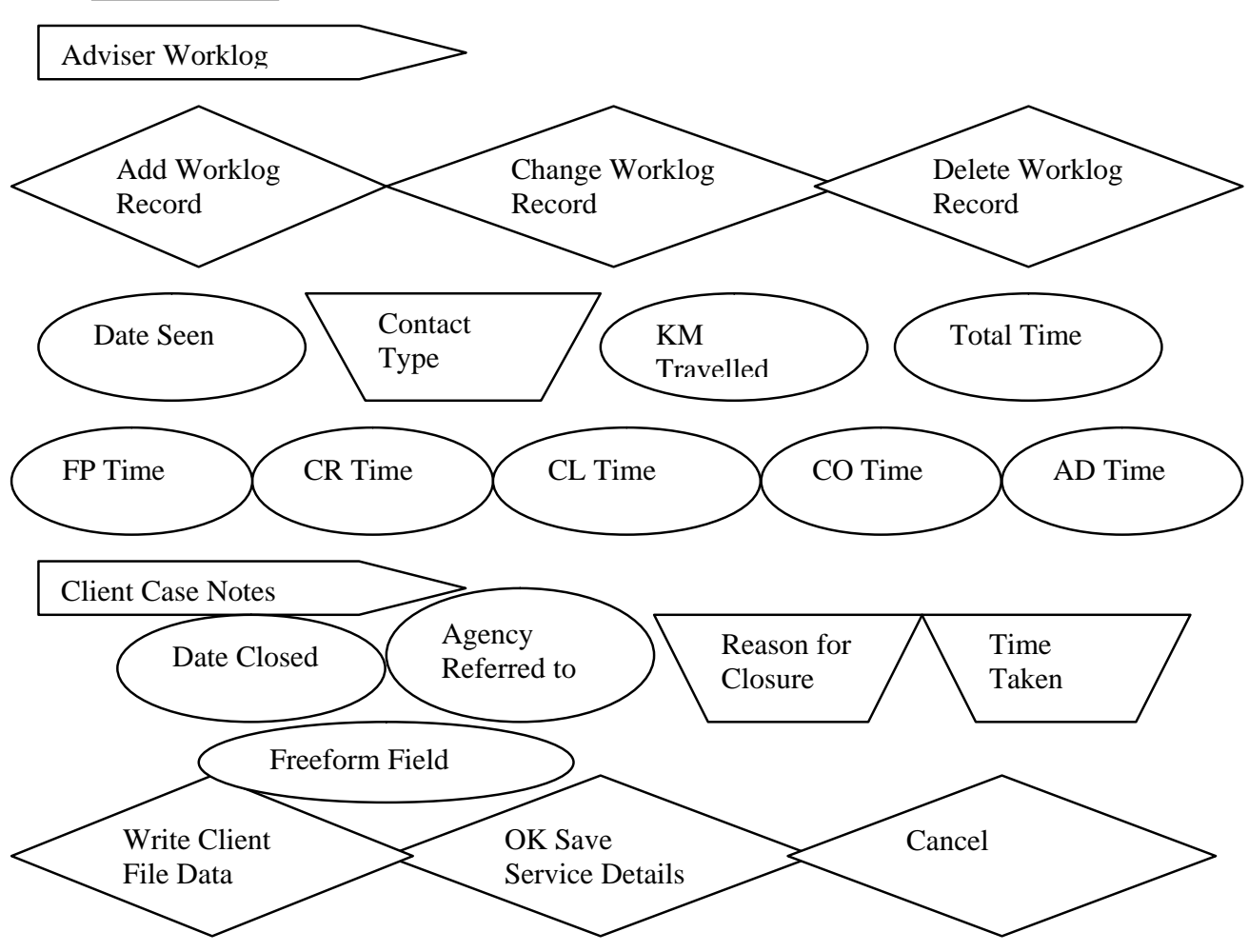


\section{Appendix v - Client Voices Project Specification - Extract}

\subsection{Application Details}

4.3.5 Client Debt Schedule

The Client Debt Schedule tab is a display screen with the buttons; Add Debt Record, Change Debt Record, Delete Debt Record, and Print Debt Schedule

List of Creditors is a display screen accessed by clicking the add button above, which has 2 buttons; Select and Close

The Add Creditor Record Screen has the following 14 fields

Name freeform field up to 60 characters

Address is 3 freeform fields with up to 40 characters with the third field set to cap

Contact Name freeform field up to 30 characters

Contact Number phone field

Account Number freeform field up to 20 characters

NB the above fields are populated by choosing Select from List of Creditors. If Close is chosen then the fields are empty and saving the record writes the above data to the List of Creditors for future use.

NB Contact Name, Contact Number, and Account Number MUST be excluded from the data dump Total Debt dollar field

Total Arrears dollar field

Repayment Rate dollar field

Frequency dropdown with options; Weekly, Fortnightly, 4 Weekly, Quarterly, Monthly, Annually

Priority dropdown with options; 1-20 (or a scroll field 1-20 as per CMS)

Security dropdown with options; 01 Secured, 02 Unsecured

Creditor dropdown with options; 01 Government Department, 02 Courts, 03 Telecommunications, 04

Utilities, 05 Accommodation, 06 Retail Goods, 07 Professional Services, 08 Bank Loans, 09 Finance

Company Loans, 10 Bank Mortgages, 11 Family/Friend/Other Loans

Type dropdown with options; 01 Credit Card, 02 Credit Contract, 03 Loans, 04 Other

Add to Budget Worksheet tick box

NB this tick box ensures data is written to the budget worksheet when saved

4.3.6 Adviser Worklog

The Adviser Worklog tab is a display screen with the buttons; Add Worklog Record, Change Worklog

Record, Delete Worklog Record, and Print Adviser Worklog

The Add Worksheet Record and Change Worksheet Record screens are accessed by clicking add or change from the Adviser Worklog tab and have the following 9 fields.

Date Seen date field

Contact Type dropdown with options; Office, Home, Phone

KM Travelled numeric field

Total Time two numeric subfields; $\mathrm{hr}$ and $\mathrm{m}$ (where $\mathrm{m}$ is 1-59)

FP Time two numeric subfields; $\mathrm{hr}$ and $\mathrm{m}$ (where $\mathrm{m}$ is $1-59$ )

CR Time two numeric subfields; $\mathrm{hr}$ and $\mathrm{m}$ (where $\mathrm{m}$ is $1-59$ )

$C L$ Time two numeric subfields; $h r$ and $\mathrm{m}$ (where $\mathrm{m}$ is 1-59)

CO Time two numeric subfields; $h r$ and $\mathrm{m}$ (where $\mathrm{m}$ is 1-59)

$A D$ Time two numeric subfields; $\mathrm{hr}$ and $\mathrm{m}$ (where $\mathrm{m}$ is $1-59$ )

NB when totalling the Time fields for Print Adviser Worklog the minutes will need to be counted and added in time (i.e. every $60 \mathrm{~m}$ will add $1 \mathrm{hr}$ to total)

4.3.7 Client Case Notes

The Client Case Notes tab is a freeform field using the full text limit with the following fields

Date Closed date field

Agency Referred To freeform field with 75 character limit

Reason for Closure dropdown with options; Client Needs Met, Client Referred On, Client Withdrew,

Budget Service Withdrew, Client Needs Not Met, Other: Please Specify

dropdown with options

It has the usual save/cancel buttons as well as;

It also has a button Write Client File Data, which saves the data to the harddrive and also writes the file to the data dump.

NB a data field must be completed in each of the Client Details tabs before the Write Client File Data will work, a warning screen could be displayed if incomplete 


\title{
Appendix vi - Client Voices Database Administration Tasks
}

Client Voices -

Database Administration Tasks

\begin{abstract}
Responsibility
The service is responsible for the collection and delivery of data to the Federation. The service is also responsible for the protection of all Federation resources utilised on this project and is liable for loss or damage of those resources and should have adequate insurance in place to cover such loss or damage. The service will assume responsibility for the broadband connection at the end of the project as per 'resources'. The service is responsible for all management of the project tasks conducted at the service.
\end{abstract}

\section{Reporting}

The Database Administrator reports to the service's management committee (possibly through a supervisor/coordinator/manager dependent on the service's structure). The Database Administrator also reports functionally and periodically to the Federation's project representative.

\section{Grievance Procedures}

Internal service grievances will be conducted as per the service's policy on grievances. External issues should be directed to the Federation's representative. External grievances should be made in writing to the CEO and/or the President of the Federation. The Federation will direct issues to the Database Administrator and, if need be, will make complaints directly in writing to the service's Chairperson. Please note that unresolved issues could affect the Service Agreement.

\section{Resources Provided by the Federation}

Broadband package (modem, connection, 12 month plan credit)

$\$ 678.00$

note: the broadband package is gifted to the service and the service assumes responsibility for the ongoing costs (or disconnection) of the broadband service after the initial 12 months

Client Voices System software license

Forms and stationery

Training

Full copy of final report

$\$ 650.00$

Total value of the resource package per service

$\$ 48.00$

$\$ 810.00$

$\$ 15.00$

$\$ 2,197.00$

\section{Project Management}

The service is responsible for overseeing the project tasks conducted at the service as per the Service Agreement. Management of the project tasks will ensure the smooth running of the new processes that need to be put in place at the service. The Coordinator/Manager is probably best placed to manage the project, although it may be appropriate to have a management committee member or sub-committee oversee the project. Note that in smaller services the Project Manager and the Database Administrator may be the same person. Project management will include, but not be limited to, the following:

Work with Federation representative to set up the workstation

Put in place a Database Administrator to input data

Ensure all advisers are made aware of the new processes with emphasis on the client case note form and process

Keep service and adviser records up-to-date

Ensure initial interviews are conducted in such a way as to collect the necessary service statistics

Ensure all Advisers use Federation forms and processes to collect data from clients

Ensure all initial information is recorded by the Administrator

Ensure all participating ongoing client data is recorded by the Administrator

Allow the Database Administrator to be available for training

Be available, along with the appropriate staff, to give input into the final report

\section{Database Administration Tasks}

This section focuses on those tasks that need to be completed by the Database Administrator to satisfy the Service Agreement. The following list of tasks is non-exhaustive and further tasks may be included as they are identified.

\section{Training:}

An initial training course will be conducted that will cover, in depth, the running of the programme and all associated processes. The training will probably take place in small groups around the country so some travel and possibly overnight accommodation will be required. This initial training must be attended by all persons responsible for inputting data into the database and failure to make the training will automatically terminate the Service Agreement. As noted above all associated costs will be covered by the Federation.

Review of the Manual:

A comprehensive user manual will be handed out at the training and will need to be read thoroughly by the Database Administrator. 


\section{Appendix vi - Client Voices Database Administration Tasks}

Initial Setup:

Setup passwords

Input service record data

Setup staff records

Setup adviser records with passwords

Ongoing Data Entry:

Input all initial interview records

Input budget items and debt schedules for all participating ongoing clients

Input case notes for ongoing clients

Deliver datasets periodically to the Federation

Database Maintenance:

Keep all records (service, staff, and clients) up-to-date

Make all changes to database fields within five working days of a Task Request

Respond by email to all Task Requests within five working days

Submit email Requests to the Federation for all database and process issues (the Federation will respond to all Ticket Requests within five working days)

Project Tasks:

Be available for input into Federation project reports to funders

Be available for further forums (whether they be virtual or real time) to discuss ideas/issues with other Client Voices System users. The Federation will manage some sort of email list for forum purposes.

CVS Metrics and Reports:

There will be a number of reports and graphs that the programme and Excel can produce to measure various service metrics. Examples include staff numbers and movement, client numbers and movement, total arrears as a percentage of total debt, levels of debt to creditors over time, and a number of other metrics. These tasks will require further specialist knowledge and are beyond the scope of this project, however, a good level of Excel knowledge would enable service metric keeping.

The metrics provide very valuable management tools and predictors and very solid research can be used for funding applications. Their potential is probably the most valuable aspect of the project for services and the Federation will continue to work toward accumulating and passing on this knowledge over the term of the project. 